Supporting Information for:

\title{
Redox State Dependent Interplay between Pendant Group and Conducting Polymer Backbone in Quinone-Based Conducting Redox Polymers for Lithium Ion Batteries
}

Huan Wang, ${ }^{\text {a }}$ Rikard Emanuelsson, ${ }^{\text {a }}$ Haidong Liu, ${ }^{\text {b }}$ Kristina Edström, ${ }^{\text {b }}$ Fikret Mamedov, ${ }^{\mathrm{c}}$ Maria Strømme, ${ }^{a}$ and Martin Sjödin. ${ }^{\text {a* }}$

a, Nanotechnology and Functional Materials, Department of Engineering Sciences, The Ångstrom Laboratory, Uppsala University, Box 534, SE-751 21, Uppsala, Sweden

b, Department of Chemistry - Ångström, The Ångström Laboratory, Uppsala University, Box 538, SE-751 21 Uppsala, Sweden

c, Molecular Biomimetics, Department of Chemistry - Ångström, The Ångström Laboratory, Uppsala University, Box 523, SE-751 20, Uppsala, Sweden

*Martin.Sjodin@angstrom.uu.se 


\section{Synthesis and characterization of Q-EDOT, QF-EDOT, $\mathrm{QF}_{2}$-EDOT and $\mathrm{Q}\left(\mathrm{CF}_{3}\right)_{2}$-EDOT}

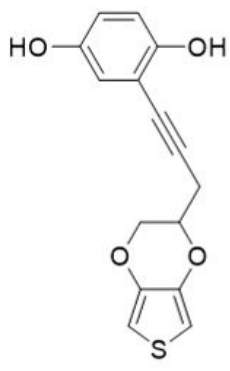

Q-EDOT

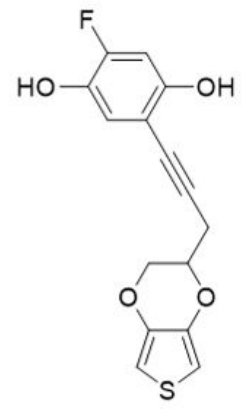

QF-EDOT

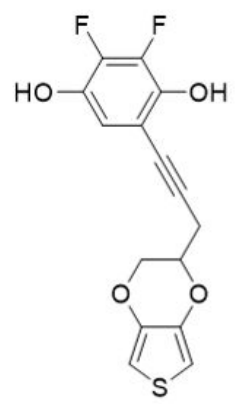

$\mathrm{QF}_{2}$-EDOT

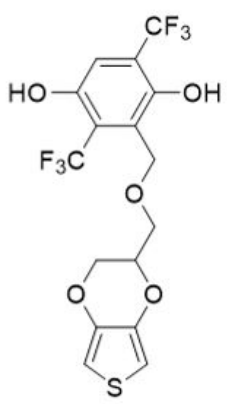

$\mathrm{Q}\left(\mathrm{CF}_{3}\right)_{2}$-EDOT

Figure S1. Structure of the substituted quinone-EDOT monomers forming the base for the CRPs under study.

Synthesis: For the fluoro-substituted quinones we followed the same methodology as we have previously used to assemble Q-EDOT ${ }^{1}$. Starting from the commercially available suitable fluorinated hydroquinone, bromination using bromine in $\mathrm{Et}_{2} \mathrm{O}$ proceeded smoothly to give 1a and 1b, respectively (Scheme 2). Then, the phenolic alcohols were THP protected using 3,4Dihydro-2H-pyran and a catalytic amount of acid (2a and $\mathbf{2 b}$ ). Sonogashira type cross-coupling with pyEDOT in a microwave reactor using our previously reported conditions gave, after deprotection of the THP groups using catalytic amount of acid in methanolic DCM, QF-EDOT and $\mathbf{Q F}_{2}$-EDOT, respectively ${ }^{2}$.The bis(trifluromethylated) hydroquinone (5) is reported ${ }^{3,4}$. However, in our hands, the trifluoromethylation of 1,4-diiodo-2,5-dimethoxybenzene into 4 using sodium trifluoroacetate and $\mathrm{CuI}$ was sluggish and significant amounts of starting materials and mono-substituted compound made separation difficult. Instead, we started with the commercially available 1,4-bis(trifluoromethyl)benzene, bormination using NBS in TFA $/ \mathrm{H}_{2} \mathrm{SO}_{4}{ }^{5,6}$ gave 1,4-bis(trifluoromethyl)-2,5-dibromomethylbenzene. Nucleophilic aromatic substitution with sodium methoxide in DMF smoothly gave 4. Demethylation of the methoxy groups needs to be done in two steps as directly treating 4 with $\mathrm{BBr}_{3}$ causes decomposition. The reported method utilizes ethanethiol ${ }^{3,4}$, however, the very potent odor of this compound makes this route unattractive. We instead employed the hydrocloride salt of 2(Dimethylamino)ethanethiol and two equivalents of base to generate the thiolate. In this way the deprotecting reagent and the formed 2-(diethylamino)ethyl methyl sulfide can be transferred into the aqueous phase by quenching with dilute acid, allowing an essentially odorless workup ${ }^{7}$. Thiolate only liberates one of the phenolic $\mathrm{OH}$ groups, the other methyl group could next be removed using $\mathrm{BBr}_{3}$ to produce 5 in very good overall yield. THP protection then gave $\mathbf{6}$. The THP group effectively assists in ortho-lithiation with $\mathrm{n}$-BuLi allowing further functionalization of the benzene ring ${ }^{8}$. Quenching the lithiated species with iodine produced a compound suitable for Sonogashira type coupling as above. Unfortunately, this compound proved unreactive under a range of conditions tested, preventing us from using the same linker between the EDOT and quinone in all compounds. Instead, a benzylic alcohol was installed as a handle by bubbling 
formaldehyde, cracked from paraformaldehyde, into the reaction mixture containing the organolithium species. Installation of the benzylic alcohol generated a number of semi-separable diasteromers, due to the sterogenic centers on the THP groups. To confirm the product, THP groups were removed under acidic conditions resulted in 3-(hydroxymethyl)-2,5bis(trifluoromethyl)benzene-1,4-diol as the only product. The benzyl alcohol isomer mixture was converted into the mesylate ester and then directly reacted with EDOT-MeOH. The complex isomer mixture prevented full characterization of the intermediates in these steps. Instead, the THP groups were removed in the final step using catalytic amount of acid in methanolic DCM which converged all isomers into $\mathbf{Q}\left(\mathbf{C F}_{3}\right)_{2}$-EDOT.

General information: Reagents were purchased from Sigma Aldrich and were used without further purification. All reactions were performed in argon atmosphere. Dichloromethane (DCM) was dried using a PureSolv PS-MD-4-EN solvent purification system and stored in nitrogen atmosphere. Analytical thin layer chromatography was performed using pre-coated Merck Silica 60 F254 plates, and compound visualization was achieved with UV light $(254 \mathrm{~nm})$. Flash Chromatography was performed on a Grace REVELERIS® X2 Flash Chromatography System using pre-packed silica cartridges ( 12 or $40 \mathrm{~g}$ ). Room temperature (RT) refers to $22{ }^{\circ} \mathrm{C}$. NMR spectra were recorded on an Agilent $400-\mathrm{MR}(1 \mathrm{H}$ at $400 \mathrm{MHz}, 13 \mathrm{C}$ at $101 \mathrm{MHz})$ or Bruker Avance Neo $(1 \mathrm{H}$ at $500 \mathrm{MHz}, 13 \mathrm{C}$ at $126 \mathrm{MHz})$. Chemical shifts are reported using the residual solvent signal as an indirect reference to TMS $\left(\mathrm{CHCl}_{3}: \delta_{\mathrm{H}}=7.26 \mathrm{ppm}, \delta_{\mathrm{C}}=77.16 \mathrm{ppm}\right.$, $\left.\left(\mathrm{CD}_{3}\right)_{2} \mathrm{CO}: \delta_{\mathrm{H}}=2.05 \mathrm{ppm}, \delta_{\mathrm{C}}=206.40 \mathrm{ppm}\right)$. Coupling constants $(J)$ are reported in Hz. High resolution MS was performed on a Waters LCT PREMIER operating in ES+ or ES- mode.<smiles>Oc1cc(Br)c(O)cc1F</smiles>

2-bromo-5-fluorobenzene-1,4-diol (1a)

2-fluorobenzene-1,4-diol (3.60 g, $28.1 \mathrm{mmol}, 1.0 \mathrm{eq})$ was mixed in $\mathrm{Et}_{2} \mathrm{O}(50 \mathrm{~mL})$ and cooled to 0C. $\mathrm{Br}_{2}(4.50 \mathrm{~g}, 28.1 \mathrm{mmol}, 1.0 \mathrm{eq})$ was dissolved in $\mathrm{Et}_{2} \mathrm{O}(20 \mathrm{~mL})$ and placed in a dropping funnel. The bromine solution was added over $15 \mathrm{~min}$ and then stirred at $0{ }^{\circ} \mathrm{C}$ for $1.5 \mathrm{~h}$ more. Thereafter the solution was poured into an ice-cold saturated solution of sodium thiosulfate. The organics were separated and dried over $\mathrm{MgSO}_{4}$. The solvent was removed under reduced pressure resulting in a pale solid $(5.4 \mathrm{~g}, 92 \%)$.

${ }^{1} \mathrm{H}$ NMR (500 MHz, d ${ }_{6}$-acetone) $\delta 8.51(\mathrm{~s}, 1 \mathrm{H}), 8.35(\mathrm{~s}, 1 \mathrm{H}), 7.14(\mathrm{~d}, J=9.2 \mathrm{~Hz}, 1 \mathrm{H}), 6.80(\mathrm{~d}, J$ $=12.0 \mathrm{~Hz}, 1 \mathrm{H})$.

${ }^{13} \mathrm{C}$ NMR (126 MHz, $\mathrm{d}_{6}$-acetone) $\delta 151.8(\mathrm{~d}, J=241.2 \mathrm{~Hz}), 148.0(\mathrm{~d}, J=9.8 \mathrm{~Hz}), 139.4(\mathrm{~d}, J=$ $13.8 \mathrm{~Hz}), 122.0(\mathrm{t}, J=3.2 \mathrm{~Hz}), 105.4(\mathrm{~d}, J=22.8 \mathrm{~Hz}), 104.2(\mathrm{~d}, J=3.4 \mathrm{~Hz})$.

HRMS (TOF MS ES-) calculated for $\mathrm{C}_{6} \mathrm{H}_{3} \mathrm{O}_{2} \mathrm{BrF}$ (M-H): $\mathrm{C}_{6} \mathrm{H}_{3} \mathrm{O}_{2} \mathrm{BrF}: 204.9300$, found: 204.9305 . 
<smiles>Fc1cc(O[IH+])c(Br)cc1O[IH+]</smiles>

2,2'-((2-bromo-5-fluoro-1,4-phenylene)bis(oxy))bis(tetrahydro-2H-pyran) (2a)

$1 \mathrm{a}(6.0 \mathrm{~g}, 28.9 \mathrm{mmol}, 1.0 \mathrm{eq})$ was dissolved in EtOAc (40 mL) and 3,4-Dihydro-2H-pyran (10 $\mathrm{mL}$ ), a few drops of trifluoroacetic acid were added and the solution stirred in RT for $24 \mathrm{~h}$. The solution was filtered over celite and $\mathrm{NH}_{4} \mathrm{Cl}(50 \mathrm{~mL}$, sat) was added. The layers were separated and the organics washed with water $(50 \mathrm{~mL})$ and brine $(50 \mathrm{~mL})$. After drying over $\mathrm{MgSO} 4$, silica was added and the solvent removed under reduced pressure. Flash chromatography (Pentane: EtOAC $0-20 \%$, gradient) gave $5.56 \mathrm{~g}(51 \%)$ of a viscous clear oil that solidified upon standing.

${ }^{1} \mathrm{H}$ NMR (500 MHz, $\left.\mathrm{cdcl}_{3}\right) \delta 7.39(\mathrm{~d}, J=8.7 \mathrm{~Hz}, 1 \mathrm{H}), 6.99(\mathrm{~d}, J=12.4 \mathrm{~Hz}, 1 \mathrm{H}), 5.38-5.33(\mathrm{~m}$, $1 \mathrm{H}), 5.34-5.28(\mathrm{~m}, \mathrm{H}), 3.99-3.92(\mathrm{~m}, 1 \mathrm{H}), 3.93-3.85(\mathrm{~m}, 1 \mathrm{H}), 3.67-3.57(\mathrm{~m}, 2 \mathrm{H}), 2.12-$ $1.77(\mathrm{~m}, 6 \mathrm{H}), 1.77-1.54(\mathrm{~m}, 6 \mathrm{H})$.

HRMS (TOF MS ES-) calculated for $\mathrm{C}_{16} \mathrm{H}_{19} \mathrm{O}_{4} \mathrm{BrF}(\mathrm{M}-\mathrm{H})^{-}: 373.0451$, found: 373.0463

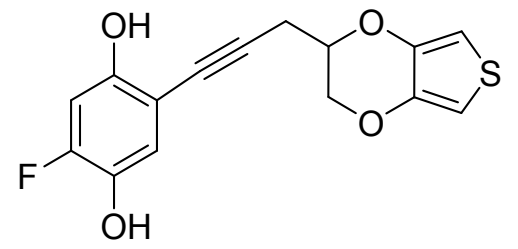

2-(3-(2,3-dihydrothieno[3,4-b][1,4]dioxin-2-yl)prop-1-yn-1-yl)-5-fluorobenzene-1,4-diol （QFEDOT)

2a (375 mg, $1.0 \mathrm{mmol}, 1.0 \mathrm{eq})$ and pyEDOT (198 mg, $1.1 \mathrm{mmol}, 1.1 \mathrm{eq})$ were added to a dry Mw-vial, equipped with a magnetic stirrer, placed under Ar. Diethylamine $(1.65 \mathrm{~mL})$ and anhydrous DMF $(1.0 \mathrm{~mL})$ was added to the vial. Thereafter, $\mathrm{PdCl}_{2}\left(\mathrm{PPh}_{3}\right)_{2},(35 \mathrm{mg}, 0.05 \mathrm{mmol}$, $0.05 \mathrm{eq}), \mathrm{CuI}$ (9.5 mg, $0.05 \mathrm{mmol}, 0.05 \mathrm{eq})$ and $\mathrm{PPh}_{3}(53 \mathrm{mg}, 0.2 \mathrm{mmol}, 0.2 \mathrm{eq})$ were added. The vial was heated in a microwave reactor at $120{ }^{\circ} \mathrm{C}$ for $25 \mathrm{~min}$. After cooling, $\mathrm{Et}_{2} \mathrm{O}(25 \mathrm{~mL})$ was added and the solution was filtered through celite. The organics were washed with $0.1 \mathrm{M} \mathrm{HCl}$ $(25 \mathrm{~mL})$ and brine $(25 \mathrm{~mL})$, dried over $\mathrm{MgSO}_{4}$. Thereafter silica was added and the solvents removed under reduced pressure. Flash chromatography (Pentane:EtOAc $0-10 \%$, gradient) was used to crudely separate the Sonogashira product. The fractions containing product was combined and the solvents removed under reduced pressure, the yellow oil was dissolved in DCM:MeOH (10 mL, 7:3) and a few drops of TFA added. After $1 \mathrm{~h}$ no starting material remained and only one major product spot was obvious on TLC (Penatne: EtOAc, 3:1). DCM $(20 \mathrm{~mL})$ was added and the organics was washed twice with $\mathrm{NaHCO}_{3}(10 \mathrm{~mL}$, sat), dried over $\mathrm{MgSO}_{4}$ and silica was added. Removal of solvent under reduced pressure and flash chromatography (Pentane:EtOAc 10\% - 50\%) resulted in a clear oil. Addition of $\mathrm{CHCl}_{3}$ resulted in precipitation of a white solid (100 mg, 32\%).

${ }^{1} \mathrm{H}$ NMR (400 MHz, d 6 -acetone) $\delta 8.15(\mathrm{~s}, 1 \mathrm{H}, \mathrm{OH}), 8.08(\mathrm{~s}, 1 \mathrm{H}, \mathrm{OH}), 6.94(\mathrm{~d}, J=9.7 \mathrm{~Hz}, 1 \mathrm{H})$, $6.67(\mathrm{~d}, J=12.1 \mathrm{~Hz}, 1 \mathrm{H}), 6.46(\mathrm{~s}, 2 \mathrm{H}), 4.43-4.37(\mathrm{~m}, 2 \mathrm{H}), 4.13(\mathrm{dd}, J=12.0,7.7 \mathrm{~Hz}, 1 \mathrm{H}), 2.99$ $-2.74(\mathrm{~m}, 2 \mathrm{H})$. 
${ }^{13} \mathrm{C}$ NMR $\left(126 \mathrm{MHz}, \mathrm{d}_{6}\right.$-acetone) $\delta 153.0(\mathrm{~d}, J=9.9 \mathrm{~Hz}), 152.9(\mathrm{~d}, J=244.0 \mathrm{~Hz}), 142.8,138.7$ $(\mathrm{d}, J=13.8 \mathrm{~Hz}), 121.6(\mathrm{~d}, J=3.4 \mathrm{~Hz}), 107.2(\mathrm{~d}, J=3.4 \mathrm{~Hz}), 104.9,104.7,100.6,100.5,89.7$ (d, $J=1.6 \mathrm{~Hz}), 78.9,73.10,68.27,22.69$.

HRMS (TOF MS ES-) calculated for $\mathrm{C}_{15} \mathrm{H}_{10} \mathrm{O}_{4} \mathrm{SF}(\mathrm{M}-\mathrm{H})=$ : 305.0284, found: 305.0291 .<smiles>Oc1cc(Br)c(O)c(F)c1F</smiles>

5-bromo-2,3-difluorobenzene-1,4-diol (1b)

2,3-difluorobenzene-1,4-diol (4.09 g, $28.0 \mathrm{mmol}, 1.0 \mathrm{eq})$ was mixed in $\mathrm{Et}_{2} \mathrm{O}(50 \mathrm{~mL})$ and cooled to $0{ }^{\circ} \mathrm{C} . \mathrm{Br}_{2}(4.47 \mathrm{~g}, 28.0 \mathrm{mmol}, 1.0 \mathrm{eq})$ was dissolved in $\mathrm{Et}_{2} \mathrm{O}(20 \mathrm{~mL})$ and placed in a dropping funnel. The bromine solution was added over $15 \mathrm{~min}$ and then stirred at $0{ }^{\circ} \mathrm{C}$ for $1.5 \mathrm{~h}$ more. Thereafter the solution was poured into an ice-cold saturated solution of sodium thiosulfate. The organics were separated and dried over $\mathrm{MgSO}_{4}$. The solvent was removed under reduced pressure giving in a pale solid $(5.7 \mathrm{~g}, 90 \%)$.

${ }^{1} \mathrm{H}$ NMR $\left(500 \mathrm{MHz}, \mathrm{CDCl}_{3}\right) \delta 6.98(\mathrm{dd}, J=8.2,2.6 \mathrm{~Hz}, 1 \mathrm{H}), 5.19(\mathrm{~s}, 1 \mathrm{H}), 5.04(\mathrm{~d}, J=2.6 \mathrm{~Hz}$, $1 \mathrm{H})$.

${ }^{13} \mathrm{C}$ NMR (126 MHz, d d $_{6}$ acetone) $\delta 143.0(\mathrm{dd}, J=181.5,12.6 \mathrm{~Hz}), 141.1(\mathrm{dd}, J=182.0,12.9 \mathrm{~Hz})$, $140.1(\mathrm{~d}, J=12.8 \mathrm{~Hz}), 137.3$ (d, $J=13.2 \mathrm{~Hz}), 115.7(\mathrm{~m}), 105.5$ (t, $J=3.6 \mathrm{~Hz})$.

HRMS (TOF MS ES-) calculated for $\mathrm{C}_{6} \mathrm{H}_{2} \mathrm{~F}_{2} \mathrm{Br}(\mathrm{M}-\mathrm{H})$ :: 222.9206, found: 222.9216.<smiles>Fc1c(OP)cc(Br)c(O[IH])c1F</smiles>

2,2'-((5-bromo-2,3-difluoro-1,4-phenylene)bis(oxy))bis(tetrahydro-2H-pyran) (2b)

2,3-bromo-5-fluorohydroquinone $(6.0 \mathrm{~g}, 26.7 \mathrm{mmol}, 1.0 \mathrm{eq})$ was dissolved in EtOAc $(40 \mathrm{~mL})$ and 3,4-Dihydro-2H-pyran $(10 \mathrm{~mL})$, a few drops of trifluroacetic acid was added and the solution stirred in $\mathrm{RT}$ for $24 \mathrm{~h}$. The solution was filtered over celite and $\mathrm{NH}_{4} \mathrm{Cl}(50 \mathrm{~mL}$, sat) was added. The layers were separated and the organics washed with water $(50 \mathrm{~mL})$ and brine $(50 \mathrm{~mL})$. After drying over $\mathrm{MgSO}_{4}$, silica was added and the solvent removed under reduced pressure. Flash chromatography (Pentane: EtOAC $0-20 \%$, gradient) gave $6.05 \mathrm{~g}(60 \%)$ of a viscous oil that solidified upon standing

${ }^{1} \mathrm{H}$ NMR $\left(500 \mathrm{MHz}, \mathrm{CDCl}_{3}\right) \delta 7.23-7.18(\mathrm{~m}, 1 \mathrm{H}), 5.43-5.39(\mathrm{~m}, 1 \mathrm{H}), 5.39-5.33(\mathrm{~m}, 1 \mathrm{H})$, $4.21-4.13(\mathrm{~m}, 1 \mathrm{H}), 3.93-3.84(\mathrm{~m}, 1 \mathrm{H}), 3.67-3.59(\mathrm{~m}, 2 \mathrm{H}), 2.13-1.77(\mathrm{~m}, 6 \mathrm{H}), 1.77-1.53$ $(\mathrm{m}, 6 \mathrm{H})$. 
<smiles>Oc1cc(C#CCC2COc3cscc3O2)c(O)c(F)c1F</smiles>

2,3-difluorobenzene-1,4-diol ( $\mathbf{Q F}_{2}$-EDOT)

5-(3-(2,3-dihydrothieno[3,4-b][1,4]dioxin-2-yl)prop-1-yn-1-yl)-

2b (393 mg, $1.0 \mathrm{mmol}, 1.0 \mathrm{eq})$ and pyEDOT (198 mg, $1.1 \mathrm{mmol}, 1.1 \mathrm{eq})$ was added to a dry Mw-vial, equipped with a magnetic stirrer, placed under Ar. Diethylamine $(1.65 \mathrm{~mL})$ and anhydrous DMF $(1.0 \mathrm{~mL})$ was added to the vial. Thereafter, $\mathrm{PdCl}_{2}\left(\mathrm{PPh}_{3}\right)_{2},(35 \mathrm{mg}, 0.05 \mathrm{mmol}$, $0.05 \mathrm{eq}), \mathrm{CuI}$ (9.5 mg, $0.05 \mathrm{mmol}, 0.05 \mathrm{eq})$ and $\mathrm{PPh}_{3}(53 \mathrm{mg}, 0.2 \mathrm{mmol}, 0.2 \mathrm{eq})$ were added. The vial was heated in a microwave reactor at $120^{\circ} \mathrm{C}$ for $25 \mathrm{~min}$. After cooling, $\mathrm{Et}_{2} \mathrm{O}(25 \mathrm{~mL})$ was added and the solution was filtered through celite. The organics were washed with $0.1 \mathrm{M} \mathrm{HCl}$ $(25 \mathrm{~mL})$ and brine $(25 \mathrm{~mL})$, dried over MgSO4. Thereafter silica was added and the solvents removed under reduced pressure. Flash chromatography (Pentane:EtOAc $0-10 \%$, gradient) was used to crudely separate the Sonogashira product. The fractions containing product was combined and the solvents removed under reduced pressure, the yellow oil was dissolved in DCM:MeOH (10 mL, 7:3) and a few drops of TFA added. After $1 \mathrm{~h}$ no starting material remained and only one major product spot was obvious on TLC (Penatne: EtOAc, 3:1). DCM $(20 \mathrm{~mL})$ was added and the organics were washed twice with $\mathrm{NaHCO}_{3}(10 \mathrm{~mL}$, sat), dried over $\mathrm{MgSO}_{4}$ and silica was added. Removal of solvent under reduced pressure and flash chromatography (Pentane:EtOAc 10\% - 50\%) resulted in a clear oil. Addition of $\mathrm{CHCl}_{3}$ resulted in precipitation of a white solid (77 $\mathrm{mg}, 24 \%)$.

${ }^{1} \mathrm{H}$ NMR (500 MHz, d 6 -acetone) $\delta 8.56(\mathrm{~s}, 2 \mathrm{H}), 6.77(\mathrm{dd}, J=9.0,2.3 \mathrm{~Hz}, 1 \mathrm{H}), 6.45(\mathrm{~s}, 2 \mathrm{H}), 4.43$ $-4.35(\mathrm{~m}, 2 \mathrm{H}), 4.13(\mathrm{dd}, J=11.9,7.7 \mathrm{~Hz}, 1 \mathrm{H}), 2.92(\mathrm{dd}, J=17.2,5.8 \mathrm{~Hz}, 1 \mathrm{H}), 2.86(\mathrm{dd}, J=$ $17.2,7.1 \mathrm{~Hz}, 1 \mathrm{H})$.

${ }^{13} \mathrm{C}$ NMR (126 MHz, d -acetone) $\delta$-at2.5, $142.5(\mathrm{dd}, J=245.4,12.7 \mathrm{~Hz}), 142.3(\mathrm{dd}, J=240.4$, $12.3 \mathrm{~Hz}), 139.3(\mathrm{dd}, J=10.7,1.8 \mathrm{~Hz}), 115.3,108.1(\mathrm{t}, J=3.9 \mathrm{~Hz}), 100.4,100.3$ (s), 90.6, 77.8 (dd, $J=4.7,2.8 \mathrm{~Hz}), 72.7,68.0,22.5$.

HRMS (TOF MS ES-) calculated for $\mathrm{C}_{15} \mathrm{H}_{9} \mathrm{O}_{4} \mathrm{~F}_{2} \mathrm{~S}(\mathrm{M}-\mathrm{H})^{-}:$: 323.0190, found: 323.0194 .

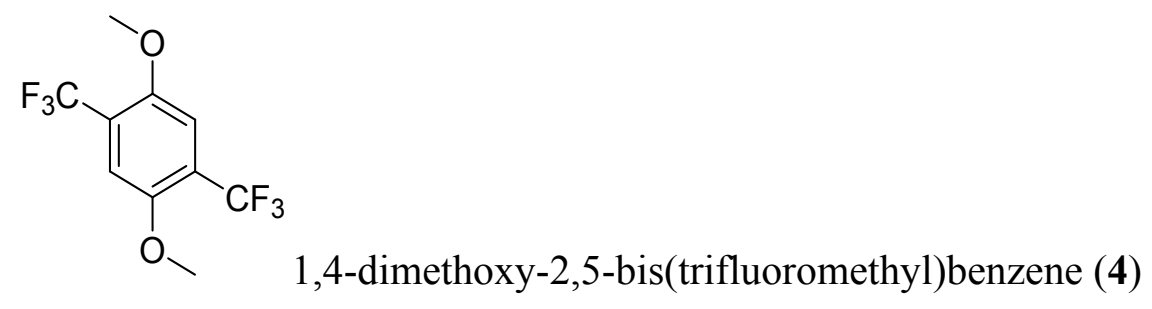

1,4-dibromo-2,5-bis(trifluoromethyl)benzene (14.2 g, $38.1 \mathrm{mmol}, 1.0 \mathrm{eq})$ was dissolved in anhydrous DMF (75 mL) and sodium methoxide (5.16 g, $95.5 \mathrm{mmol}, 2.5 \mathrm{eq})$ was added in one portion. The solution was heated at $140{ }^{\circ} \mathrm{C}$ for $16 \mathrm{~h}$. After cooling the solution was poured into $\mathrm{H}_{2} \mathrm{O}(200 \mathrm{~mL})$ and extracted with EtOAC $(2 \times 100 \mathrm{~mL})$, the organic layers were washed with 1 $\mathrm{M} \mathrm{HCl}(100 \mathrm{~mL})$ and brine $(100 \mathrm{~mL})$. Drying over $\mathrm{MgSO}_{4}$ and removal of solvent under reduced pressure gave pale brown soild $(9.7 \mathrm{~g}, 93 \%)$. NMR consistent with literature. 
${ }^{1} \mathrm{H}$ NMR (400 MHz, $\left.\mathrm{CDCl}_{3}\right) \delta 7.22(\mathrm{~s}, 2 \mathrm{H}), 3.90(\mathrm{~s}, 6 \mathrm{H})$.<smiles>Oc1cc(C(F)(F)F)c(O)cc1C(F)(F)F</smiles>

2-(Dimethylamino)ethanethiol hydrochloride (21.7 g, $127.6 \mathrm{mmol}, 5.0 \mathrm{eq})$ was dissolved in DMF (75 mL) and cooled to $0^{\circ} \mathrm{C}$. Sodium tert-butoxide $(24.5 \mathrm{~g}, 255 \mathrm{mmol}, 10 \mathrm{eq})$ was added in small portions. After addition the solution was stirred in RT for $45 \mathrm{~min}$ and then heated to $45{ }^{\circ} \mathrm{C}$. 1,4-dimethoxy-2,5-bis(trifluoromethyl)benzene (4) $(7.0 \mathrm{~g}, 25.5 \mathrm{mmol})$ was added in one portion. The temperature was raised to $65^{\circ} \mathrm{C}$ and the solution stirred for $4 \mathrm{~h}$ at this temperature and then for $2 \mathrm{~h}$ more while cooling to RT. The solution was poured into $2 \mathrm{M} \mathrm{HCl}(200 \mathrm{~mL})$ and extracted with EtOAc $(2 \times 100 \mathrm{~mL})$. The organics were washed with brine $(100 \mathrm{~mL})$ and dried over $\mathrm{MgSO}_{4}$. The solvent was removed and the solid was suspended in DCM (100 mL) and cooled to $0{ }^{\circ} \mathrm{C} . \mathrm{BBr}_{3}(12.2 \mathrm{~mL}, 31.9 \mathrm{~g}, 127.6 \mathrm{mmol}, 5.0 \mathrm{eq})$ was added dropwise. The solution was allowed to reach RT overnight and was then re-cooled to $0{ }^{\circ} \mathrm{C}$. Water was added dropwise to quench the reaction. The mixture was diluted with $1 \mathrm{M} \mathrm{HCl}(50 \mathrm{~mL})$, the organics separated, washed with brine $(50 \mathrm{~mL})$ and dried over $\mathrm{MgSO}_{4}$. The solvent was removed under reduced pressure to give a pale yellow solid (5.8 g, $92 \%)$. NMR consistent with literature.

${ }^{1} \mathrm{H}$ NMR (500 MHz, $\mathrm{d}_{6}$-acetone) $\delta 9.20(\mathrm{~s}, 2 \mathrm{H}), 7.26$ (s, 2H).

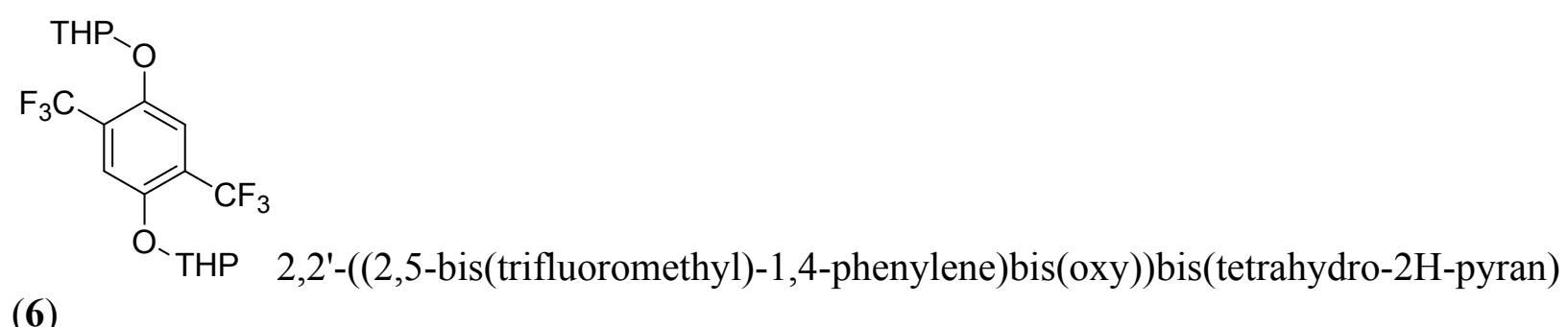

2,5-bis(trifluoromethyl)benzene-1,4-diol (6.0 g, $24.4 \mathrm{mmol}, 1.0 \mathrm{eq}, 5)$ was dissolved in dihydro$2 \mathrm{H}$-pyran $(20 \mathrm{~mL})$, and a catalytic amount of pyridinium $p$-toluenesulfonate was added. The solution was stirred in RT for $72 \mathrm{~h}$. EtOAc and silica was added and the solvents removed under reduced pressure, flash chromatography (Pentane:EtOAc $0-10 \%$, gradient) gave a white soild $(4.5 \mathrm{~g}, 45 \%)$. More polar fractions contained a mixture of mono protected and starting material and could be recycled to give more product.

${ }^{1} \mathrm{H}$ NMR (400 MHz, $\left.\mathrm{cdcl}_{3}\right) \delta 7.49$ (br s, 2H), 5.48 (d, $\left.J=2.6 \mathrm{~Hz}, 2 \mathrm{H}\right), 3.83(\mathrm{td}, J=11.1,5.6 \mathrm{~Hz}$, $2 \mathrm{H}), 3.68-3.60(\mathrm{~m}, 2 \mathrm{H}), 2.09-1.79(\mathrm{~m}, 6 \mathrm{H}), 1.78-1.57(\mathrm{~m}, 6 \mathrm{H})$.

${ }^{13} \mathrm{C} \mathrm{NMR}\left(126 \mathrm{MHz}, \mathrm{CDCl}_{3}\right) \delta 148.8,123.4(\mathrm{q}, J=31.5 \mathrm{~Hz}), 123.0(\mathrm{q}, J=273.3 \mathrm{~Hz}), 115.0(\mathrm{q}, J$ $=5.8 \mathrm{~Hz}), 97.2,61.8,30.1,25.2,18.1$.

HRMS (TOF MS ES-) calculated for $\mathrm{C}_{18} \mathrm{H}_{19} \mathrm{O}_{4} \mathrm{~F}_{6}(\mathrm{M}-\mathrm{H})^{-:}: 413.1188$, found: 413.1190. 
<smiles>Oc1cc(C(F)(F)F)c(O)c(COCC2COc3cscc3O2)c1C(F)(F)F</smiles>

\section{EDOT-MeO-2,5-bis(trifluoromethyl)benzene-1,4-diol (Q(CF $)_{2}$-EDOT)}

6 (4.50 g, $10.9 \mathrm{mmol})$ was dissolved in anhydrous THF $(150 \mathrm{~mL})$, cooled to $-78{ }^{\circ} \mathrm{C}$ and $2.5 \mathrm{M}$ nBuLi $(6.5 \mathrm{~mL}, 16.3 \mathrm{mmol})$ was added dropwise. After addition, the cooling bath was removed and the solution allowed to reach RT over $3 \mathrm{~h}$. Then it was re-cooled to $0{ }^{\circ} \mathrm{C}$. Separately, paraformaldehyde $(10 \mathrm{~g})$ was placed in a two-necked round-bottomed flask and connected to the reaction flask containing THF with a gas adapter, Teflon tubing and a Pasteur pipette to allow the cracked formaldehyde to bubble into the THF solution. A piece of glass-wool was placed in the gas adapter to act as a filter. Positive pressure of $\mathrm{Ar}$ was maintained and the paraformaldehyde was heated to $140{ }^{\circ} \mathrm{C}$ for $20 \mathrm{~min}$ allowing the cracked formaldehyde to transfer into the THF solution. The reaction solution was then stirred to RT overnight, whereupon water was added $(100 \mathrm{~mL})$ and the mixture extracted thrice with $\mathrm{Et}_{2} \mathrm{O}(3 \times 100 \mathrm{~mL})$. The organic layers were combined, washed with brine, and dried over $\mathrm{MgSO}_{4}$. Silica was added and the solvent removed under reduced pressure. Flash chromatography (Pentane:EtOAc, 0 $30 \%$, gradient) separated an oil $(2.3 \mathrm{~g}, 7)$ containing a mixture of diasteromers. To confirm product a sample was mixed with DCM:MeOH (7:3) and a trace amount of TFA added to remove the THP groups. ${ }^{1} \mathrm{H}$ NMR after removal of solvent yielded only one set of signal consistent with 3-(hydroxymethyl)-2,5-bis(trifluoromethyl)benzene-1,4-diol.

${ }^{1} \mathrm{H}$ NMR $\left(500 \mathrm{MHz}, \mathrm{CDCl}_{3}\right) \delta 7.18(\mathrm{~s}, 1 \mathrm{H}), 5.06$ (s, 2H).

HRMS (TOF MS ES-) calculated for $\mathrm{C}_{9} \mathrm{H}_{5} \mathrm{O}_{3} \mathrm{~F}_{6}(\mathrm{M}-\mathrm{H})^{-}:$275.0143, found: 275.0144 .

The benzyl alcohol diastereomer mixture 7 (2.1 g, $4.9 \mathrm{mmol})$ was dissolved in DCM (20 $\mathrm{mL})$ and cooled to $0{ }^{\circ} \mathrm{C}, \mathrm{Et}_{3} \mathrm{~N}(0.75 \mathrm{~mL}, 5.4 \mathrm{mmol}, 1.1 \mathrm{eq})$ and methansulfonyl chloride $(0.42 \mathrm{~mL}, 5.4$ mmol, $1.1 \mathrm{eq}$ ) was added dropwise and the solution stirred for $3 \mathrm{~h}$ at $0{ }^{\circ} \mathrm{C}$. Water was added and the organic layer separated, washed with brine and dried over $\mathrm{MgSO}_{4}$. Anhydrous DMF (5 mL) was added and the DCM was removed under reduced pressure to form solution A. Separately, EDOT-MeOH (1.1 g, $6.9 \mathrm{mmol}, 1.4 \mathrm{eq})$ was dissolved in anhydrous DMF (10 mL) and cooled to $0{ }^{\circ} \mathrm{C}$ to form solution B. Sodium tert-butoxide $(0.66 \mathrm{~g}, 6.9 \mathrm{mmol}, 1.4 \mathrm{eq})$ was added in portions and the solution stirred first at RT, and after $30 \mathrm{~min}$ at $45^{\circ} \mathrm{C}$ for $15 \mathrm{~min}$. Subsequently, solution A was added dropwise to solution B while heating at $45^{\circ} \mathrm{C}$. Heating was continued for $16 \mathrm{~h}$. Then, $0.1 \mathrm{M} \mathrm{HCl}(20 \mathrm{~mL})$ and $\mathrm{Et}_{2} \mathrm{O}(2 \times 50 \mathrm{~mL})$ was added and the organics separated, washed with brine and dried over $\mathrm{MgSO}_{4}$. Silica was added and the solvents removed under reduced pressure. Flash chromatography (Pentane:EtOAc, 0 - 30\%, gradient) separated several fractions containing product diastereomers 8. These were combined (1.6 $\mathrm{g}$ in total), dissolved in DCM:MeOH $(7: 3,10 \mathrm{~mL})$ and a few drops of TFA added. The solution was stirred for $15 \mathrm{~min}$, after which no starting material remained and only one major product spot was obvious on TLC (Penatne: EtOAc, 3:1). DCM (20 mL) was added and the organics were washed twice with $\mathrm{NaHCO}_{3}\left(10 \mathrm{~mL}\right.$, sat), dried over $\mathrm{MgSO}_{4}$ and silica was added. Removal of solvent under reduced pressure and flash chromatography (Pentane:EtOAc 10\% - 50\%, gradient) resulted in an clear oil. Addition of $\mathrm{CHCl}_{3}$ precipitated a white solid (250 mg, 12\%). 
${ }^{1} \mathrm{H}$ NMR (500 MHz, d 6 -acetone) $\delta 8.91(\mathrm{~s}, 1 \mathrm{H}), 8.50(\mathrm{~s}, 1 \mathrm{H}), 7.31(\mathrm{~s}, 1 \mathrm{H}), 6.44(\mathrm{~m}, 2 \mathrm{H}), 4.96(\mathrm{~m}$, 2H), $4.44(\mathrm{~m}, 1 \mathrm{H}), 4.30(\mathrm{dd}, J=11.8,2.2 \mathrm{~Hz}, 1 \mathrm{H}), 4.07$ (dd, $J=11.8,7.4 \mathrm{~Hz}, 1 \mathrm{H}), 3.90(\mathrm{~m}, 2 \mathrm{H})$.

${ }^{13} \mathrm{C}$ NMR (126 MHz, d 6 -acetone) $\delta 149.8(\mathrm{~s}, \mathrm{C}-\mathrm{OH}), 148.55$ (s, C-OH), 142.56 (s), $142.36(\mathrm{~s})$, 126.71 (s), 125.02 (q, $\left.J=275.8 \mathrm{~Hz} . \mathrm{CF}_{3}\right), 123.92$ (q, $\left.J=272.4 \mathrm{~Hz}, \mathrm{CF}_{3}\right), 123.22$ (q, $J=32.3 \mathrm{~Hz}$ ), $119.41(\mathrm{q}, J=29.6 \mathrm{~Hz}), 116.53(\mathrm{q}, J=5.3 \mathrm{~Hz}), 100.51(\mathrm{~s}), 100.39$ (s), 73.43 (s), 70.07 (s), 67.30 (q, $J=4.8 \mathrm{~Hz}, \mathrm{Ar}-\mathrm{CH} 2), 66.41(\mathrm{~s})$.

HRMS (TOF MS ES-) calculated for $\mathrm{C}_{16} \mathrm{H}_{11} \mathrm{O}_{5} \mathrm{~F}_{6} \mathrm{~S}$ (M-H)": 429.0231, found: 429.0224 . 


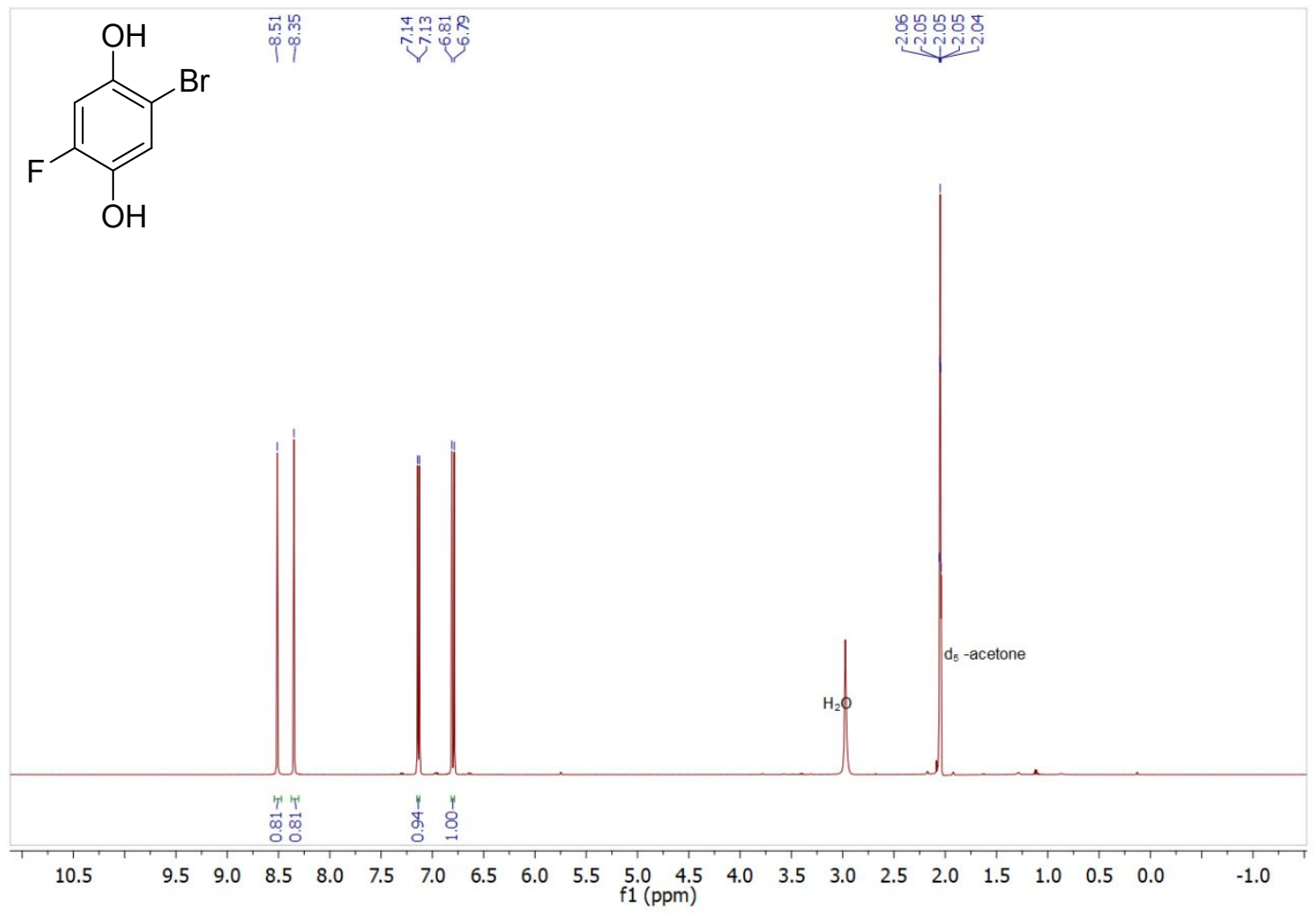

Figure S2. ${ }^{1} \mathrm{H}$ NMR spectra of 1 a recorded in $\mathrm{d}_{6}$-acetone.

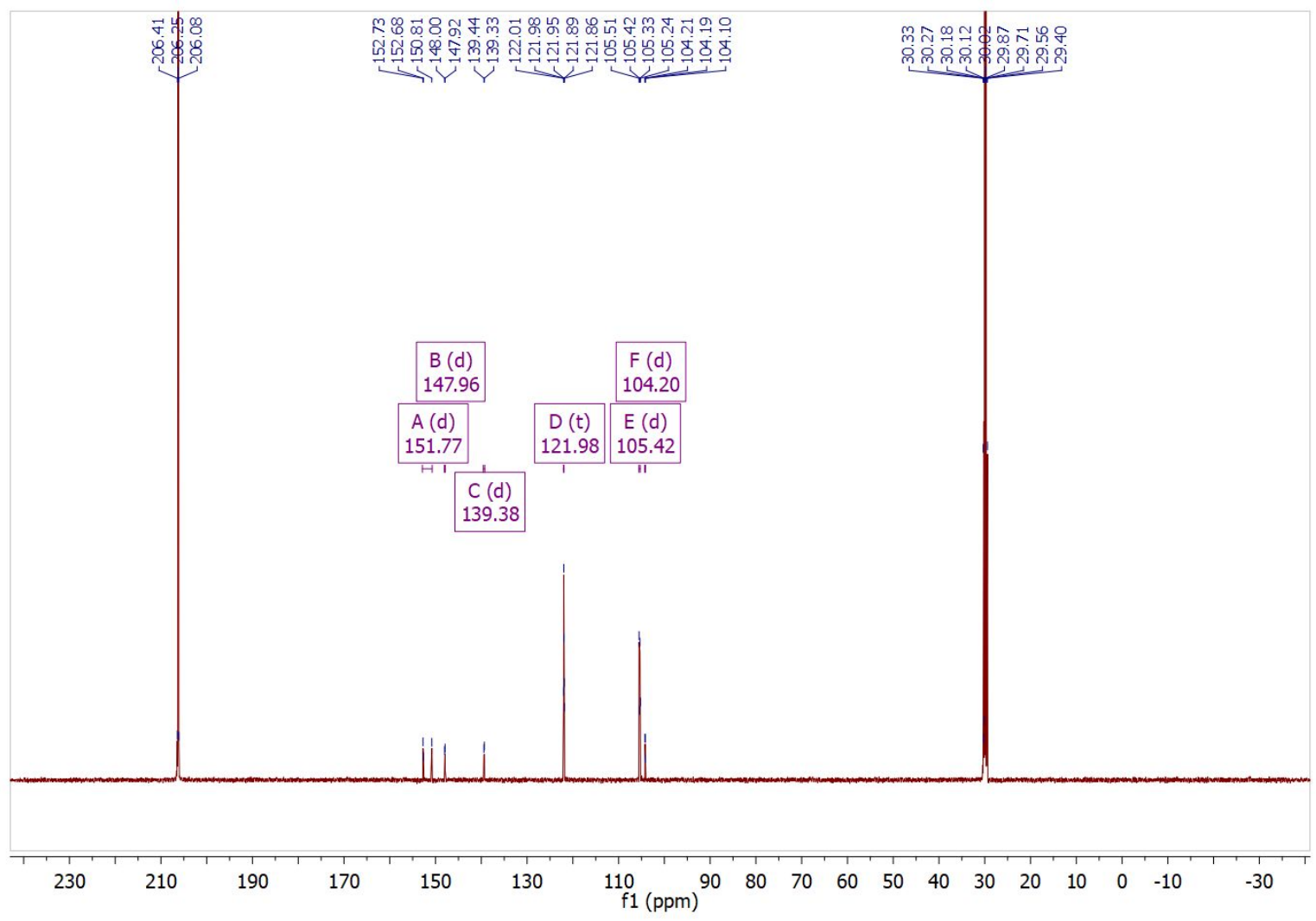

Figure S3. ${ }^{13} \mathrm{C}$ NMR (bottom) of 1 a recorded in $\mathrm{d}_{6}$-acetone. 

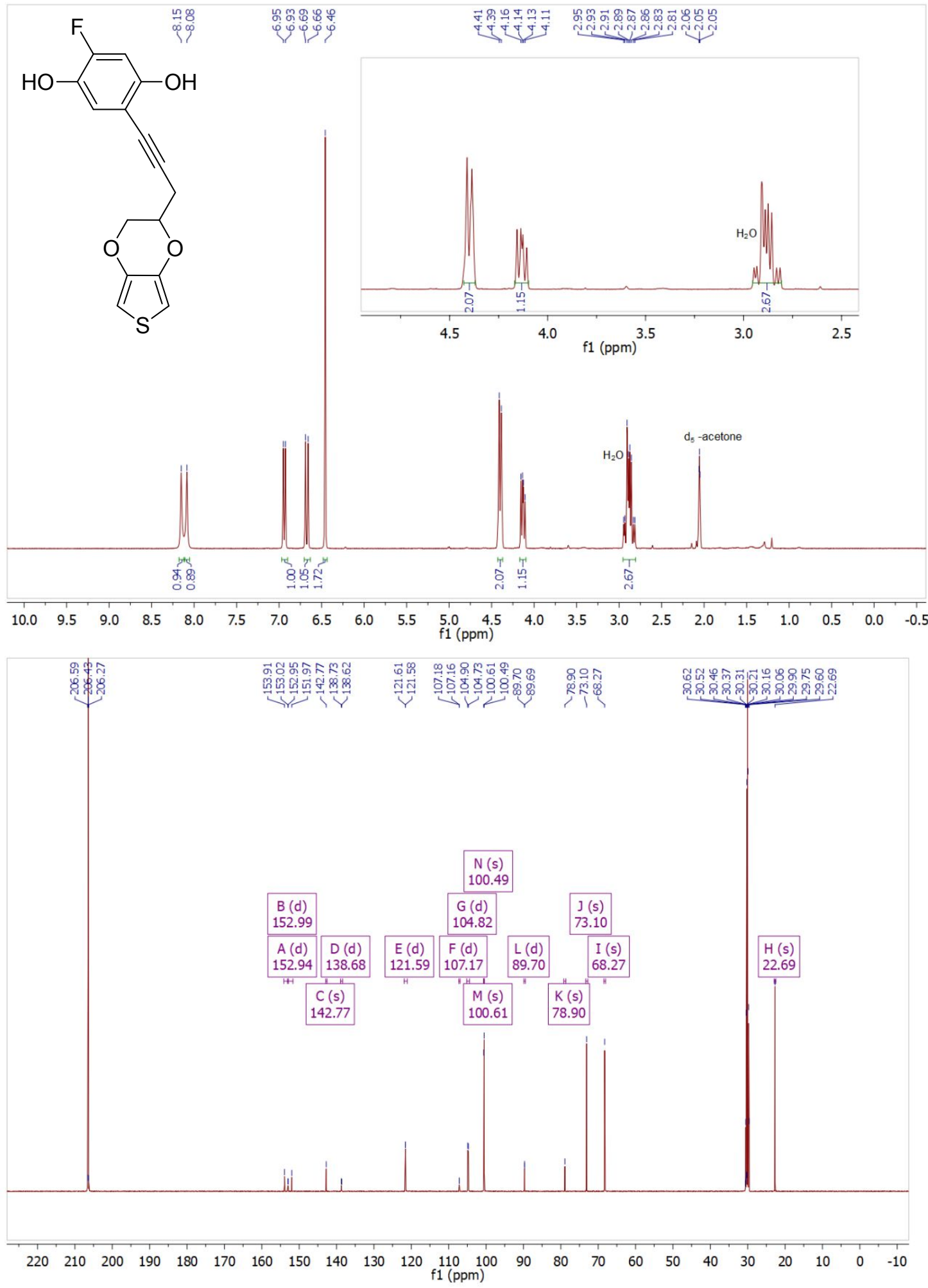

Figure S4. NMR spectra of ${ }^{1} \mathrm{H}$ NMR (top) and ${ }^{13} \mathrm{C}$ NMR (bottom) of QF-EDOT recorded in $\mathrm{d}_{6^{-}}$ acetone. 

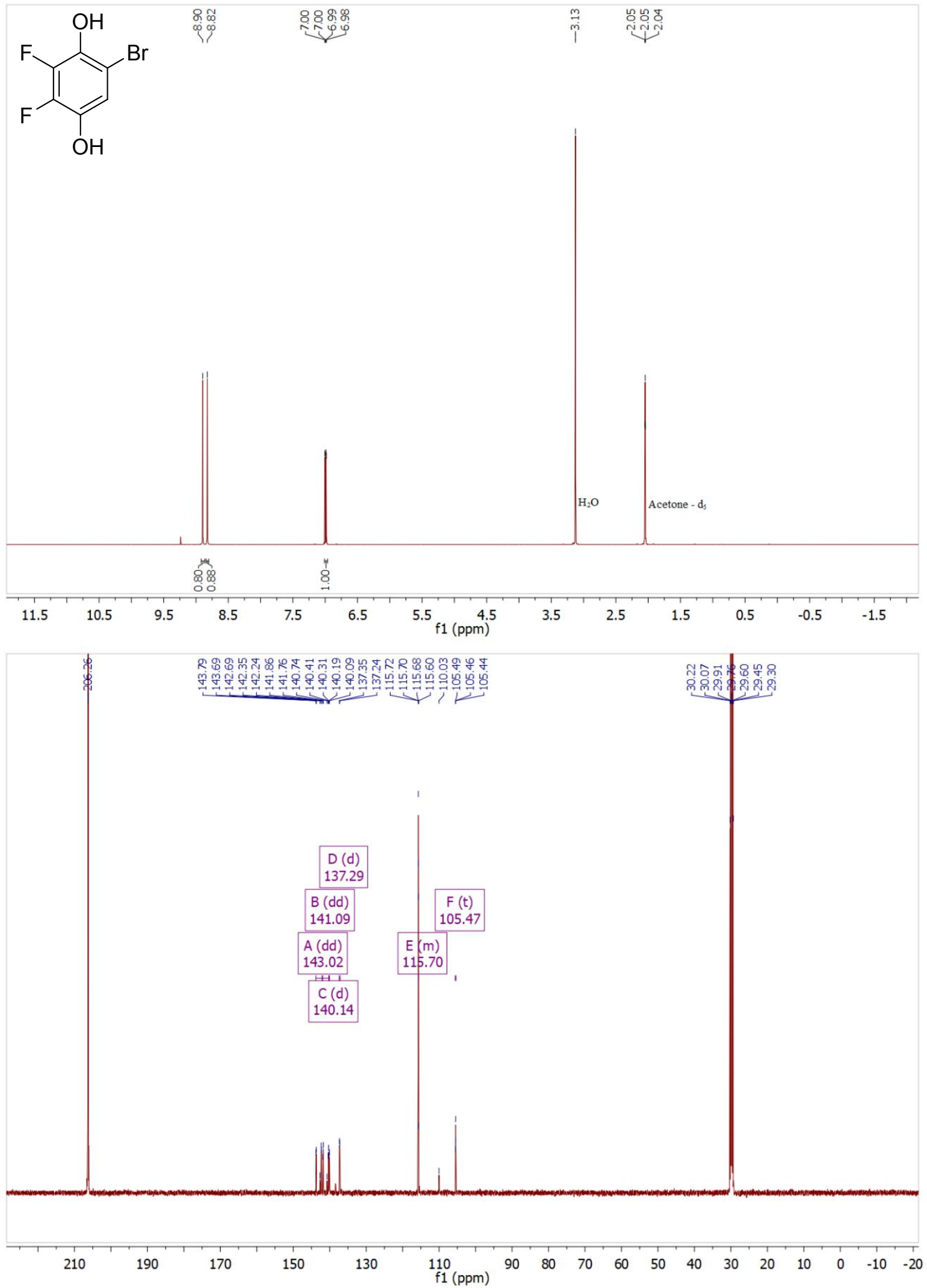

Figure S5. NMR spectra of ${ }^{1} \mathrm{H}$ NMR (top) and ${ }^{13} \mathrm{C}$ NMR (bottom) of $\mathbf{1 b}$ recorded in $\mathrm{d}_{6}$-acetone. 

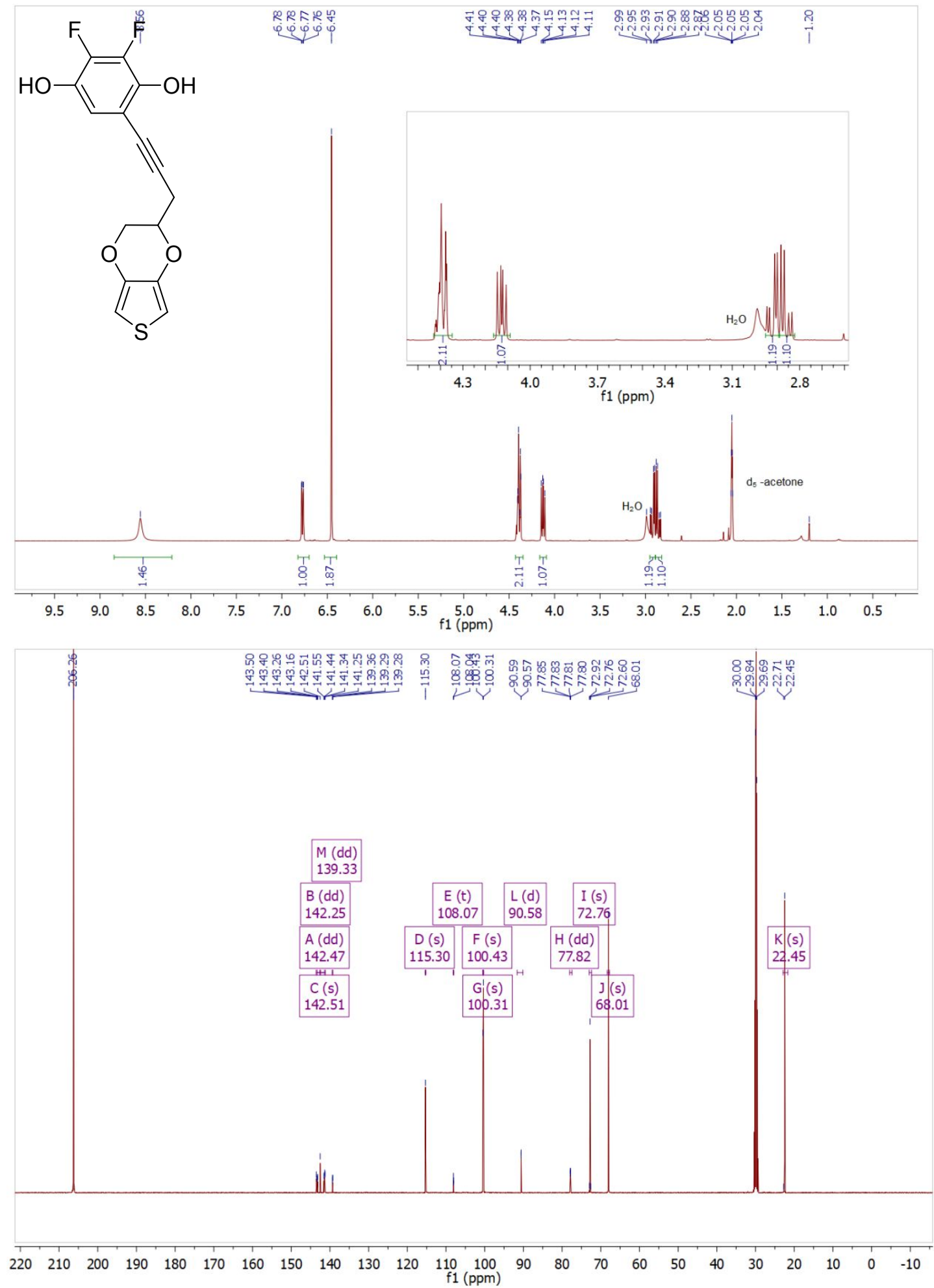

Figure S6. NMR spectra of ${ }^{1} \mathrm{H}$ NMR (top) and ${ }^{13} \mathrm{C}$ NMR (bottom) of $\mathrm{QF}_{2}$-EDOT recorded in $\mathrm{d}_{6}$-acetone. 

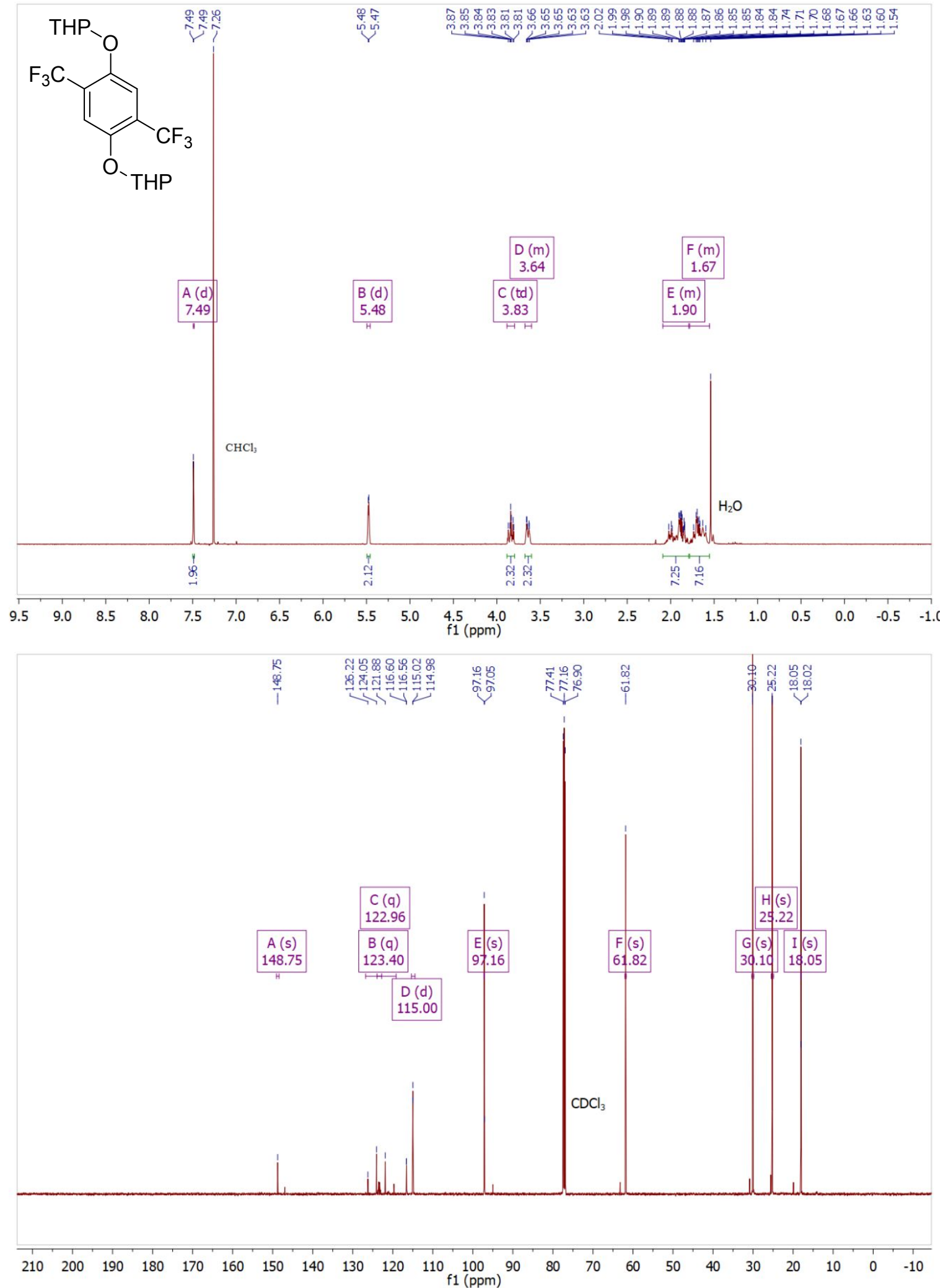

Figure S7. NMR spectra of ${ }^{1} \mathrm{H}$ NMR (top) and ${ }^{13} \mathrm{C}$ NMR (bottom) of 6 recorded in $\mathrm{CDCl}_{3}$. 

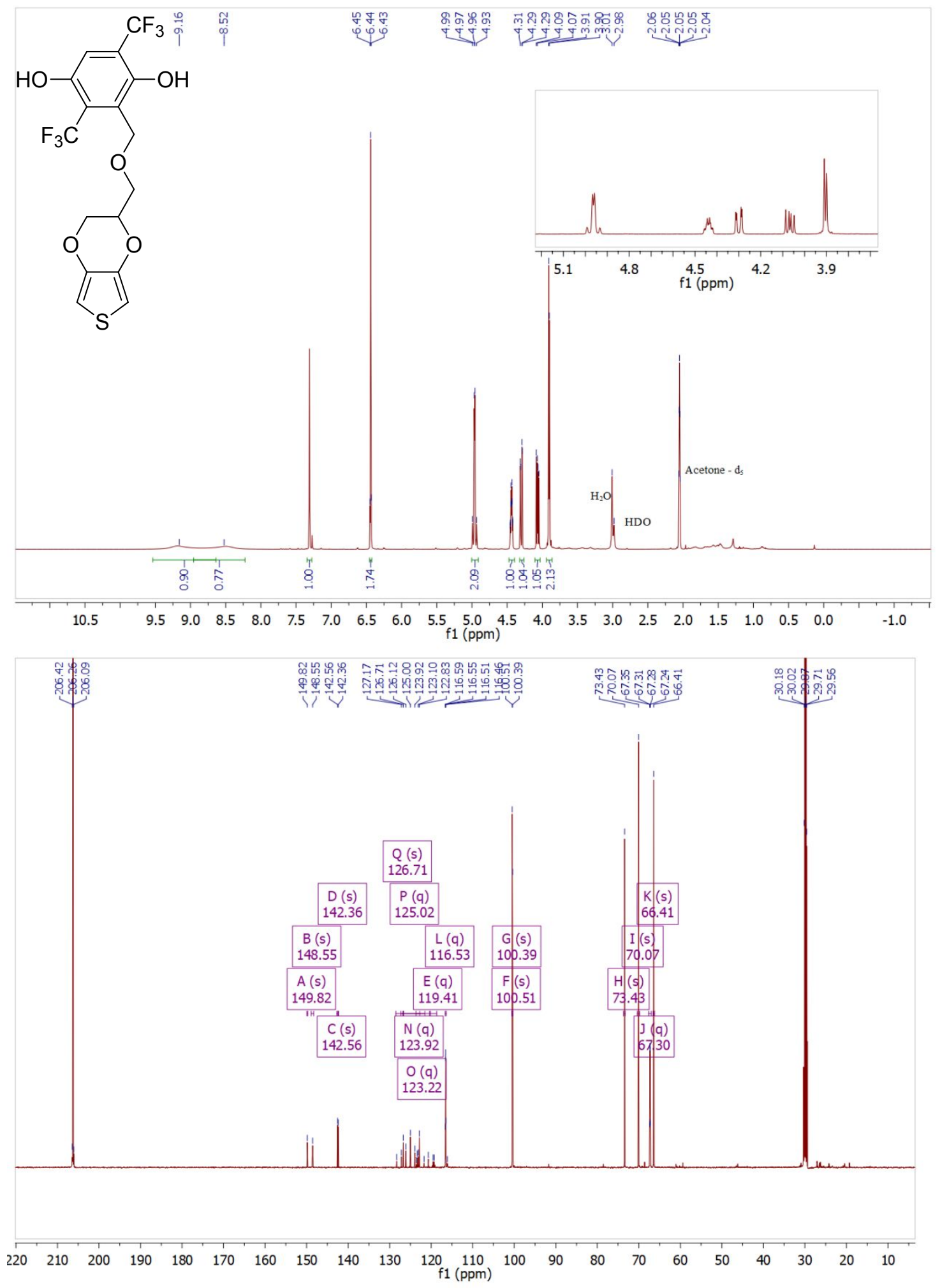

Figure S8. NMR spectra of ${ }^{1} \mathrm{H}$ NMR (top) and ${ }^{13} \mathrm{C}$ NMR of $\mathbf{Q}\left(\mathbf{C F}_{3}\right)_{2}$-EDOT (bottom) recorded in $\mathrm{d}_{6}$-acetone. 


\section{Supplemental experimental information}

\section{In situ Conductance Measurement}

A four-electrode setup was used for the in situ conductance measurements together with an Autolab PGSTAT302N potentiostat (Ecochemie, The Netherlands) equipped with a bipotentiostat module. The two working electrodes (WEs) are interdigitated array (IDA thickness $300 \mathrm{~nm}$ )(Micrux (Spain)), with 90 pairs of interdigitated Au strips with $10 \mu \mathrm{m}$ width and $150 \mathrm{~nm}$ height, separated by $10 \mu \mathrm{m}$ gaps, and with a circular active area with a diameter of $3.5 \mathrm{~mm}$. An $\mathrm{Ag} / \mathrm{Ag}^{+}\left(10 \mathrm{mM} \mathrm{AgNO} 3,0.1 \mathrm{M} \mathrm{TBAPF}_{6}\right)$ electrode in a separate compartment was used as reference and a Pt-wire served as counter electrode. The different monomers were polymerized from solution onto the IDA electrode by cyclic voltammetry at $0.05 \mathrm{~V} / \mathrm{s}$ for $2-3$ scans until a stable conductance was obtained. (Note that both WEs were cycled simultaneously). A potential bias of $1 \mathrm{mV}$ between the two Wes allowed the conductance to be monitored during the polymerization reaction (see figure S22-S26). For polymer tests in monomer free solution, the potential bias was $10 \mathrm{mV}$ and the scan rate was $0.05 \mathrm{~V} / \mathrm{s}$. The scan rate was kept sufficiently small so that the current responses from the two electrodes were dominated by the current passing through the polymer, thus ensuring that currents due to the redox conversion of the polymer layer, passing through the external auxiliary electrode, could be neglected. The conductance $\mathrm{G}$ could then be calculated using the following equation ${ }^{9}$ :

$$
\mathrm{G}=\frac{\Delta \mathrm{i}}{2 \mathrm{E}_{\mathrm{bias}}}
$$

where $\Delta i$ is the current difference between the two WEs and $\mathrm{E}_{\text {bias }}$ is the bias potential. The conversion currents, i.e. currents due to the redox conversion of the polymer layers passing through the external circuit, were calculated from the sum of current from the two Wes thus reconstructing the cyclic voltammetry response from the polymer during in situ conductance measurements (see figure S22-S26).

\section{Electrochemical quartz crystal microbalance}

Electrochemical quartz crystal microbalance (EQCM) measurements were conducted and the mass was calculated using the same method on a VersaSTAT 3 potentiostat/galvanostat (Princeton Applied Research, USA) together with a QCM922A quartz crystal microbalance (Princeton Applied Research, USA). The WE consisted of a gold-coated AT-cut quartz EQCM crystal ( $6 \mathrm{MHz}, 13.6 \mathrm{~mm}$ overall diameter, $6.7 \mathrm{~mm}$ diameter of the electroactive area). A holder was used to support the electrolyte, the gold electrode was put under the holder and the reference and counter electrodes were immersed in the electrolyte. During the polymerization and polymer characterization, the frequency change on the EQCM crystal was recorded and converted to mass change using the Sauerbrey equation ${ }^{1,10}$ (Eq. (2)). The mass change was recorded when the frequency was stable.

$$
\Delta \mathrm{m}=\Delta \mathrm{f} \frac{\mathrm{A}\left(\rho_{\mathrm{q}} * \mathrm{u}_{\mathrm{q}}\right)^{1 / 2}}{2\left(\mathrm{Fq}^{2}\right)}
$$

where $\Delta \mathrm{m}$ is the mass change, $\Delta \mathrm{f}$ is the frequency change, $\mathrm{Fq}$ is the reference frequency, $\mathrm{A}$ is the area of the active surface, $\rho_{\mathrm{q}}$ is the quartz crystal density, and $\mathrm{u}_{\mathrm{q}}$ is the AT-cut quartz constant. Thin films were used to ensure the validity of the Sauerbrey equation. A change in charge (C) 
during an electrochemical process can be converted to molar charge (mol) change by dividing with the Faraday constant $(96485 \mathrm{C} / \mathrm{mol})$. The mass change $(\mathrm{g})$ was plotted against molar charge (mol), resulting in linear regions for which slopes $(\mathrm{g} / \mathrm{mol})$ gave the molecular weight value.

\section{In situ UV-vis}

An indium tin oxide (ITO) $(8 * 30 * 1.1 \mathrm{~mm},<5 \mathrm{ohms} / \mathrm{sq})$ coated quartz slide was used as WE before electrochemical polymerization. ITO was immersed in $1 \mathrm{M}$ potassium acetate for $24 \mathrm{~h}$ and rinsed by water before electrochemical polymerization. Polymerization was performed by cyclic voltammetry as described above. The in situ spectroelectrochemical measurements were performed in a quartz cuvette with $1 \mathrm{~cm}$ path length, using $0.1 \mathrm{M} \mathrm{LiClO}_{4} / \mathrm{MeCN}$ as electrolyte. $\mathrm{Pt}$ counter and reference electrodes were put at the top of quartz and below the solution. An amperometric i-t technique in the CHI660 electrochemical working station was used to keep the polymer at a certain potential and an Agilent 8453 spectrophotometer was used to record the absorbance between 225 and $1100 \mathrm{~nm}$. A blank ITO wad used to remove background absorbance before sample measurement. The absorption data present below is a deduction between the measured absolute absorbance at a given potential and the absorbance at neutral state $-1.2 \mathrm{~V}$ $\left(\mathrm{vs} . \mathrm{Fc}^{+} / \mathrm{Fc}^{0}\right)$.

\section{Polymerization CVs on GC electrodes for PEDOT, Q-PEDOT, QF-EDOT, $\mathbf{Q F}_{2}$-EDOT and $\mathrm{Q}\left(\mathrm{CF}_{3}\right)_{2}$-EDOT}

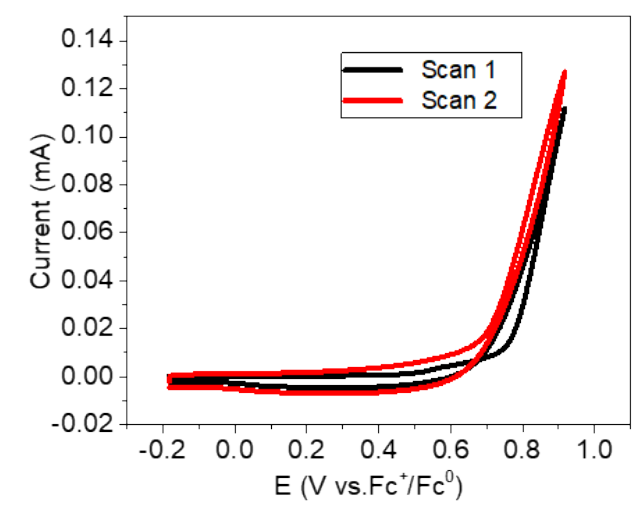

Figure S9. polymerization of PEDOT onto GC in $5 \mathrm{mM}$ monomer $0.1 \mathrm{M} \mathrm{TBAPF}_{6} / \mathrm{MeCN}$ electrolyte, scan rate: $0.1 \mathrm{~V} / \mathrm{s}$. at ambient conditions with the electrolyte purged with $\mathrm{N}_{2}$ prior to measurements, dry solution. 


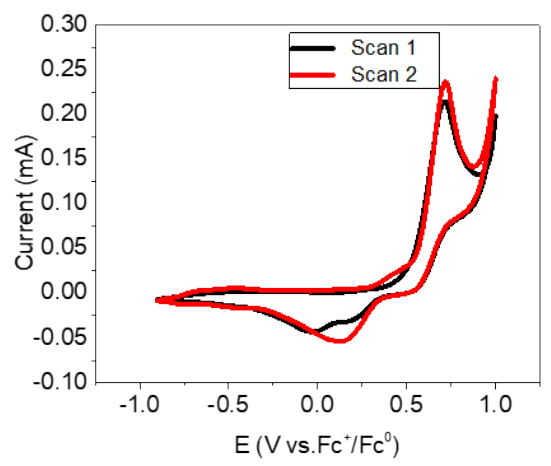

Figure S10. polymerization of Q-PEDOT onto $\mathrm{GC}$ in $5 \mathrm{mM}$ monomer $0.1 \mathrm{M} \mathrm{TBAPF}_{6} / \mathrm{MeCN}^{\mathrm{m}}$ electrolyte, scan rate: $0.1 \mathrm{~V} / \mathrm{s}$.

Figure S10 shows the polymerization CV of Q-PEDOT onto GC Peaks centered around $0.7 \mathrm{~V}$ and $0 \mathrm{~V}$ is quinone redox peak, where original proton on monomer hydroquinone is cycled. The large peak separation results from slow proton diffusion in $\mathrm{TBAPF}_{6} / \mathrm{MeCN}$ electrolyte environment. Current around $1 \mathrm{~V}$ results from the irreversible monomer oxidation. Current around $-0.5 \mathrm{~V}$ and $0 \mathrm{~V}, 0.7 \mathrm{~V}$ builds up, which is attributed to PEDOT and quinone pendant redox reaction (proton cycling), suggesting the polymer grows on glassy carbon.

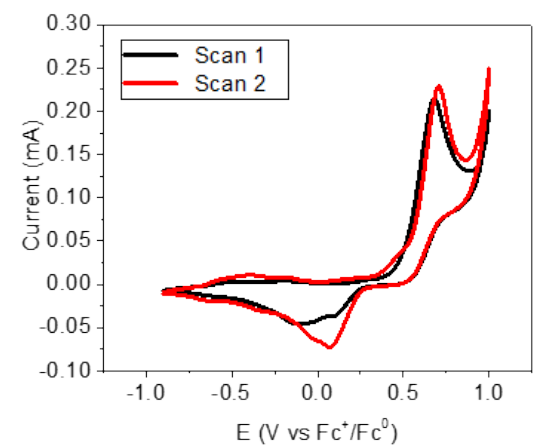

Figure S11. polymerization of QF-PEDOT onto GC in $5 \mathrm{mM}$ monomer $0.1 \mathrm{M} \mathrm{TBAPF}_{6} / \mathrm{MeCN}^{\mathrm{N}}$ electrolyte, scan rate: $0.1 \mathrm{~V} / \mathrm{s}$.

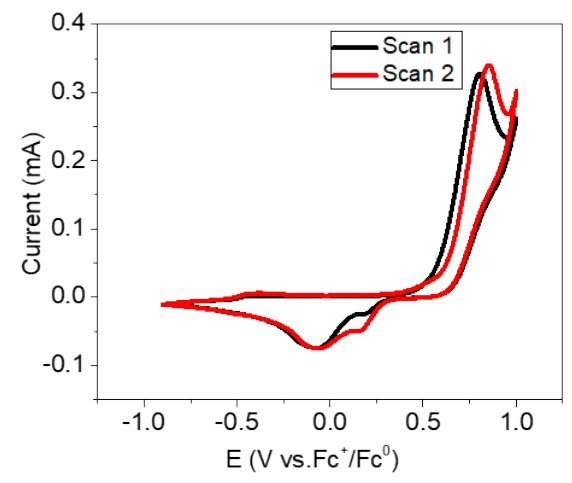


Figure S12. polymerization of $\mathrm{QF}_{2}$-PEDOT onto $\mathrm{GC}$ in $5 \mathrm{mM}$ monomer $0.1 \mathrm{M} \mathrm{TBAPF}_{6} / \mathrm{MeCN}$ electrolyte, scan rate: $0.1 \mathrm{~V} / \mathrm{s}$.

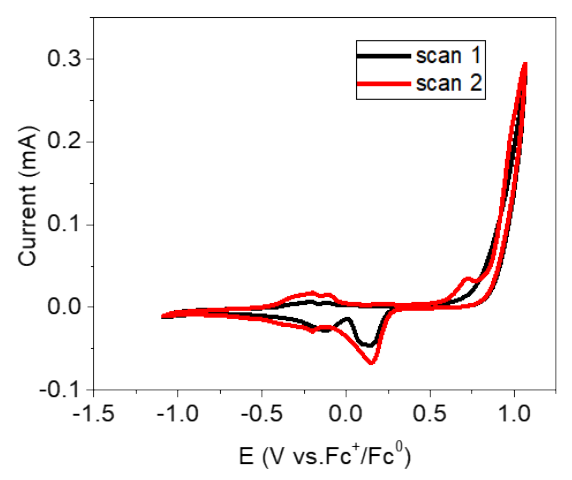

Figure S13. polymerization of $\mathrm{Q}\left(\mathrm{CF}_{3}\right)_{2}$-PEDOT onto $\mathrm{GC}$ in $5 \mathrm{mM}$ monomer $0.1 \mathrm{M}$ $\mathrm{TBAPF}_{6} / \mathrm{MeCN}$ electrolyte, scan rate: $0.1 \mathrm{~V} / \mathrm{s}$.

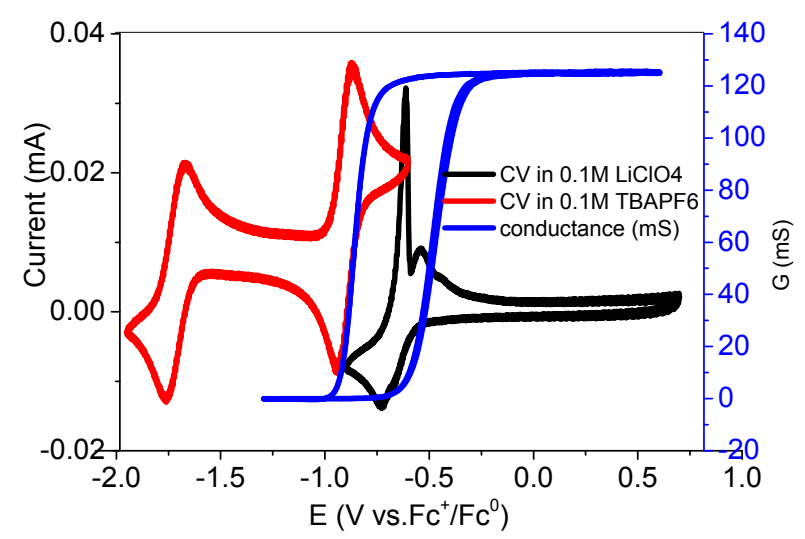

Figure S14. $\mathrm{CV}$ of $0.1 \mathrm{mM}$ quinone in $\mathrm{TBAPF}_{6} / \mathrm{MeCN}$ (red), $\mathrm{LiClO}_{4} / \mathrm{MeCN}$ (black) at the scan rate of $0.1 \mathrm{~V} / \mathrm{s}$. PEDOT conductance (blue) is tested in $\mathrm{LiClO}_{4} / \mathrm{MeCN}$ on a bare $\mathrm{GC}$.

Figure $\mathrm{S} 14$ shows the $\mathrm{CV}$ of a non-substituted quinone dissolved in $\mathrm{TBAPF}_{6} / \mathrm{MeCN}$ and $\mathrm{LiClO}_{4} / \mathrm{MeCN}$. There are two one-electron transfer processes, one at $-1.75 \mathrm{~V}$ and one at $-0.9 \mathrm{~V}$ when cycling $\mathrm{TBA}^{+}$and the peaks are shifted to much lower potentials as compared to when lithium ions are cycled. Hence, in $\mathrm{TBAPF}_{6} / \mathrm{MeCN}$ electrolyte the separation between the first and the second redox reaction is around $0.9 \mathrm{~V}$ and in the $\mathrm{CV}$ presented in the current work we only cover the first reduction. 


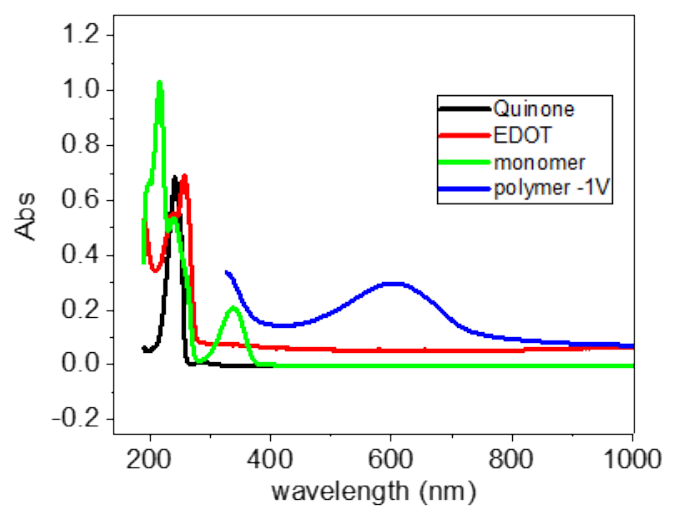

Figure15. UV-vis of free quinone molecule, EDOT and monomer $\left(\mathrm{H}_{2} \mathrm{Q}-\mathrm{PEDOT}\right)$ dissolved in $0.1 \mathrm{M} \mathrm{LiClO}_{4} / \mathrm{MeCN}$, and Q-PEDOT polymer film at $-1 \mathrm{~V}$ in $0.1 \mathrm{M} \mathrm{LiClO}_{4} / \mathrm{MeCN}$.

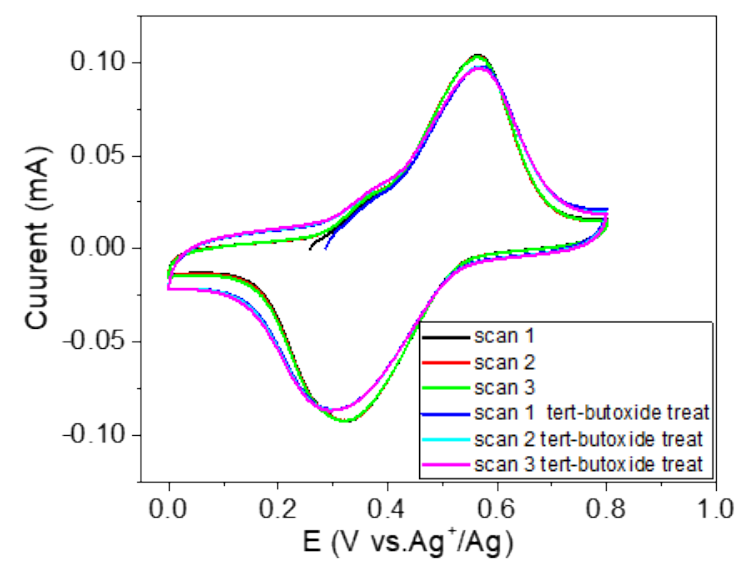

Figure S16. First three scans CV of fresh QF-PEDOT polymer film (black, red and green); QFPEDOT polymer film after lithium tert-butoxide treatment (blue, cyan and pink) tested in $0.5 \mathrm{M}$ $\mathrm{H}_{2} \mathrm{SO}_{4} / \mathrm{H}_{2} \mathrm{O}$ on a bare $\mathrm{GC}$.

In order to clarify the lithium tert-butoxide treatment effect on polymer film, we tested the CV of of QF-PEDOT polymer film before and after lithium tert-butoxide treatment (Figure S16). It shows that this treatment does not cause any considerable damage to the polymer film from the perspective of capacity or stability.

Supplementary experimental results for PEDOT, QF-EDOT, $Q F_{2}-E D O T$ and $Q\left(C_{3}\right)_{2}$ EDOT 


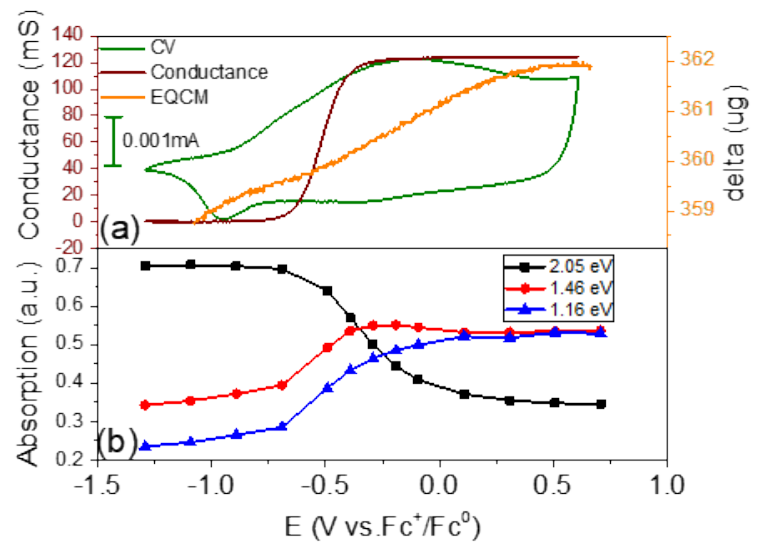

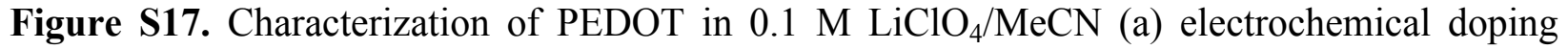
induced backbone conductance (brown, tested on Au-IDA, 0.05V/s), cyclic voltammetry (green$\mathrm{GC}, 0.1 \mathrm{~V} / \mathrm{s}$ ), polymer mass change during polymer backbone and quinone oxidation scan on EQCM (Au) measurement (orange, $0.1 \mathrm{~V} / \mathrm{s}$ ), (b) the difference absorbance in in situ UV-vis (ITO) as function of potential

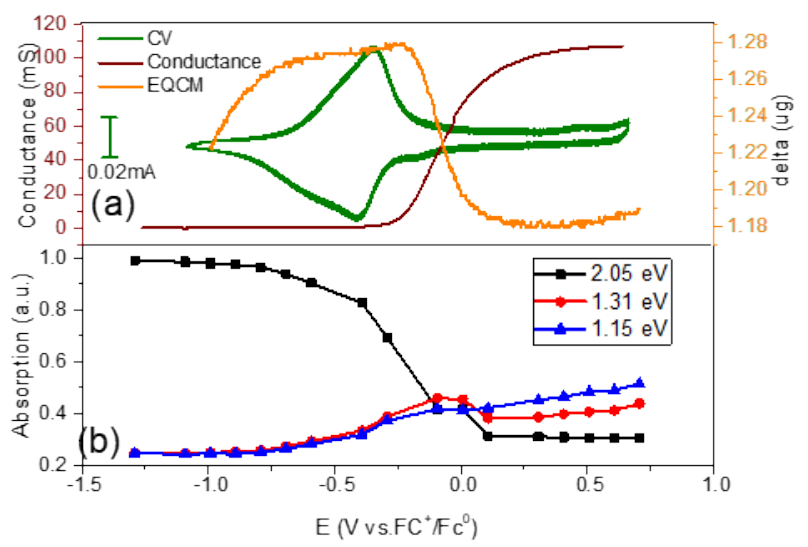

Figure S18. Characterization of QF-PEDOT in $0.1 \mathrm{M} \mathrm{LiClO}_{4} / \mathrm{MeCN}$ (a) electrochemical doping induced backbone conductance (brown, tested on Au-IDA, $0.05 \mathrm{~V} / \mathrm{s}$ ), cyclic voltammetry (green$\mathrm{GC}, 0.1 \mathrm{~V} / \mathrm{s}$ ), polymer mass change during polymer backbone and quinone oxidation scan on EQCM (Au) measurement (orange, $0.1 \mathrm{~V} / \mathrm{s}$ ), (b) the difference absorbance in in situ UV-vis (ITO) as function of potential 


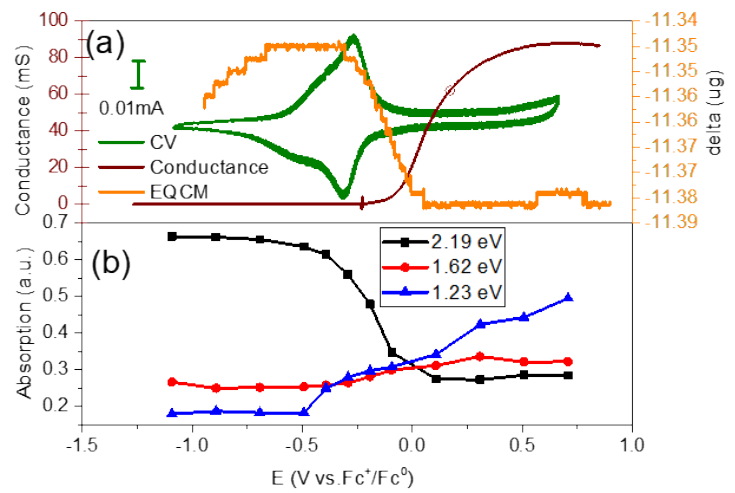

Figure S19. Characterization of $\mathrm{QF}_{2}$-PEDOT in $0.1 \mathrm{M} \mathrm{LiClO}_{4} / \mathrm{MeCN}$ (a) electrochemical doping induced backbone conductance (brown, tested on Au-IDA, 0.05V/s), cyclic voltammetry (green-GC, $0.1 \mathrm{~V} / \mathrm{s}$ ), polymer mass change during polymer backbone and quinone oxidation scan on EQCM (Au) measurement (orange, $0.1 \mathrm{~V} / \mathrm{s}$ ), (b) the difference absorbance in in situ UV-vis (ITO) as function of potential

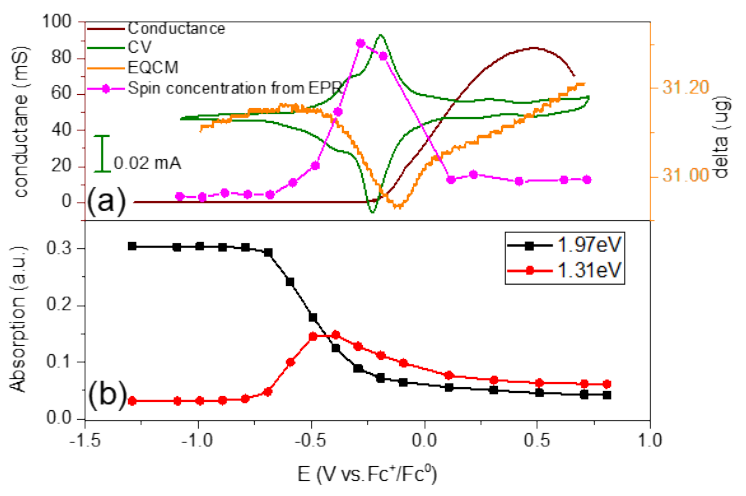

Figure S20. Characterization of $\mathrm{Q}\left(\mathrm{CF}_{3}\right)_{2}-\mathrm{PEDOT}$ in $0.1 \mathrm{M} \mathrm{LiClO}_{4} / \mathrm{MeCN}$ (a) electrochemical doping induced backbone conductance (brown, tested on Au-IDA, 0.05V/s), cyclic voltammetry (green-GC, $0.1 \mathrm{~V} / \mathrm{s}$ ), polymer mass change during polymer backbone and quinone oxidation scan on $\operatorname{EQCM}(\mathrm{Au})$ measurement (orange, $0.1 \mathrm{~V} / \mathrm{s}$ ), spin concentration change (on Pt wire) during polymer backbone and quinone oxidation scan (pink), (b) the difference absorbance in in situ UV-vis (ITO) as function of potential 

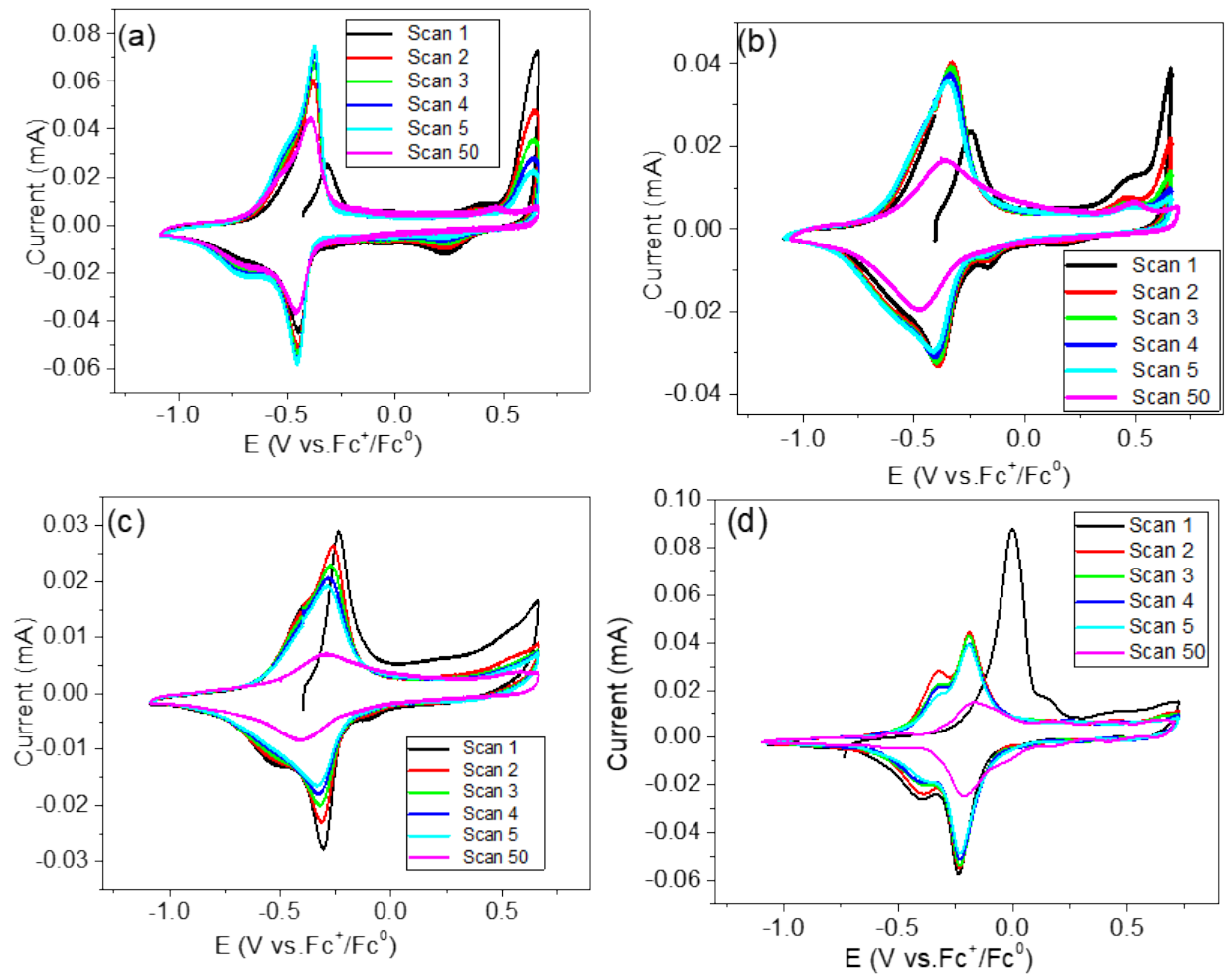

Figure S21: First 5 scans as well as scan number 50 of a fresh polymer at $0.1 \mathrm{~V} / \mathrm{s}$ in $0.1 \mathrm{M}$ $\mathrm{LiClO}_{4} / \mathrm{MeCN}$ on GC for a) Q-PEDOT, b) QF-EDOT, c) QF $\mathrm{Q}_{2}-\mathrm{EDOT}$ and d) Q(CF 3$)_{2}$-EDOT.

Table S1. doping starting-potential $\left(\mathrm{E}^{\mathrm{d}} \mathrm{V} \quad \mathrm{vs} . \mathrm{Fc}^{+} / \mathrm{Fc}^{0}\right)$ of corresponding polymers in $\mathrm{LiClO}_{4} / \mathrm{MeCN}$ from different measurements). $\mathrm{E}^{\mathrm{G}}$ : potential where conductivity start to increase. $\mathrm{E}^{\mathrm{p}}$ in $\mathrm{UV}$-vis is defined at the potential where absorbance at bandgap peak start to decrease. $\mathrm{E}^{\mathrm{p}}$ in EQCM is defined at the potential where mass start to increase. $E^{p}$ in EPR is potential where polaron concentration starts to increase. $\mathrm{E}^{0}\left(\mathrm{Li}_{2} \mathrm{Q} / \mathrm{LiQ}\right)$ and $\mathrm{E}^{0}(\mathrm{LiQ} / \mathrm{Q})$ is redox potential of corresponding redox reactions, the value is obtained from $\mathrm{CV}$.

\begin{tabular}{lccccc}
\hline $\mathrm{E}^{0} \mathrm{vs} \mathrm{Fc}^{+} / \mathrm{Fc}^{0}$ & PEDOT & Q-PEDOT & QF-PEDOT & $\mathrm{QF}_{2}-\mathrm{PEDOT}$ & $\mathrm{Q}\left(\mathrm{CF}_{3}\right)_{2}-\mathrm{PEDOT}$ \\
\hline $\mathrm{E}^{\mathrm{G}}(\mathrm{IDA})$ & -0.75 & -0.58 & -0.54 & -0.42 & -0.31 \\
$\mathrm{E}^{\mathrm{p}}(\mathrm{EPR})$ & $/$ & $/$ & $/$ & $/$ & -0.7 \\
$\mathrm{E}^{\mathrm{p}}(\mathrm{uv}-\mathrm{vis})$ & -0.7 & -0.7 & -0.7 & -0.7 & -0.7 \\
$\mathrm{E}^{\mathrm{p}}(\mathrm{EQCM})$ & -1.00 & -1.00 & -1.00 & -1.00 & -1.00 \\
$\mathrm{E}^{0}\left(\mathrm{Li}_{2} \mathrm{Q} / \mathrm{LiQ}\right)$ & $/$ & -0.61 & -0.48 & -0.44 & -0.36 \\
$\mathrm{E}^{0}(\mathrm{LiQ} / \mathrm{Q})$ & $/$ & -0.42 & -0.38 & -0.29 & -0.21 \\
\hline
\end{tabular}


In situ conduction measurements during polymerization and characterization of PEDOT, Q-PEDOT, QF-EDOT, $Q F_{2}$-EDOT and $Q\left(C_{3}\right)_{2}$-EDOT
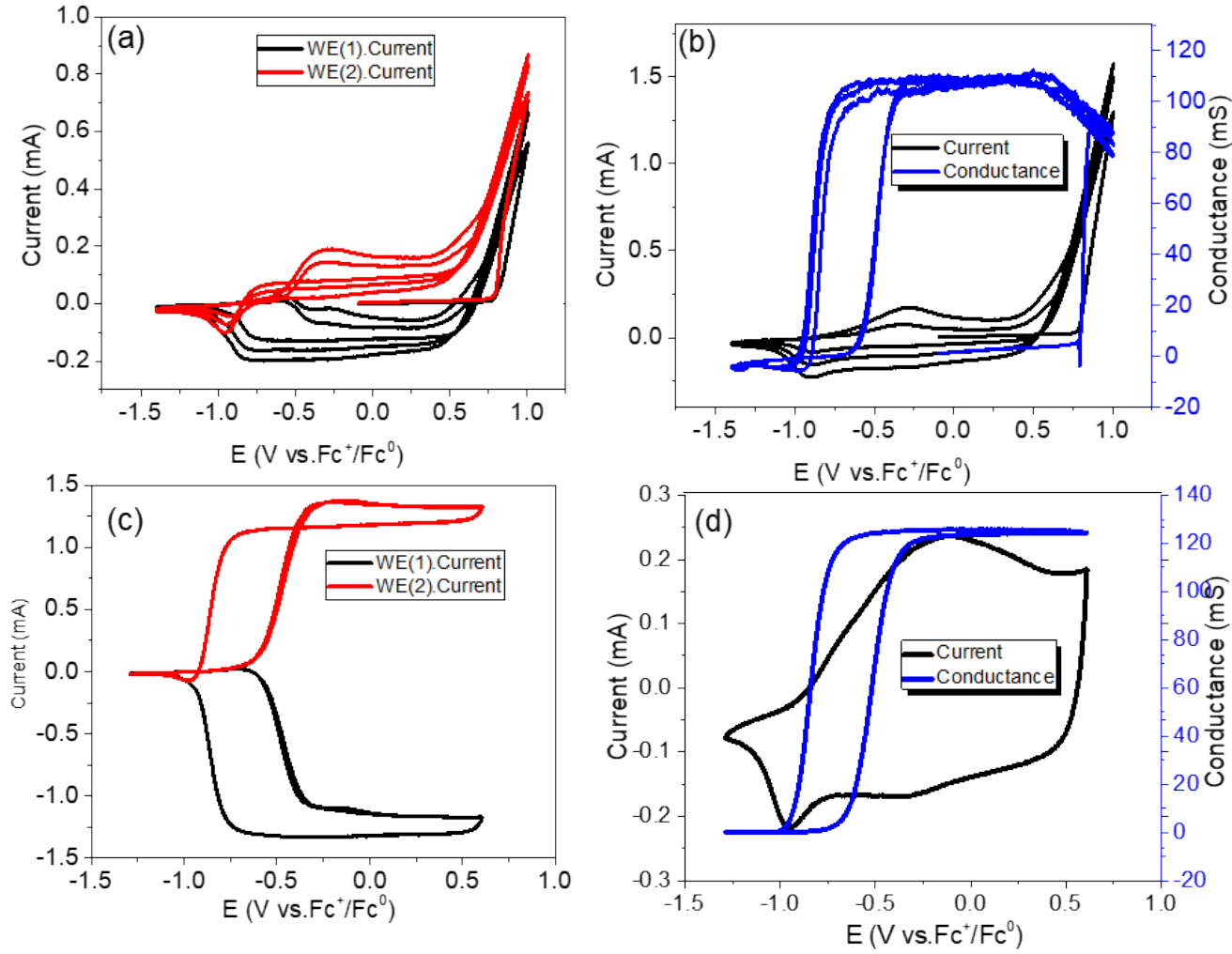

Figure S22. PEDOT (a) Current on the two working electrodes during polymerization on AuIDA in $5 \mathrm{mM}$ monomer $0.1 \mathrm{M} \mathrm{TBAPF} / \mathrm{MeCN}$ solution at $0.05 \mathrm{~V} / \mathrm{s}$ with a potential bias of $1 \mathrm{mV}$. (b) the corresponding $\mathrm{CV}$ and conductance during polymerization. (c) Current on the two working electrodes during characterization on $\mathrm{Au}-\mathrm{IDA}$ in $0.1 \mathrm{M} \mathrm{LiClO}_{4} / \mathrm{MeCN}$ solution at $0.05 \mathrm{~V} / \mathrm{s}$ with a potential bias of $10 \mathrm{mV}$. (d) the corresponding $\mathrm{CV}$ and conductance during characterization. 

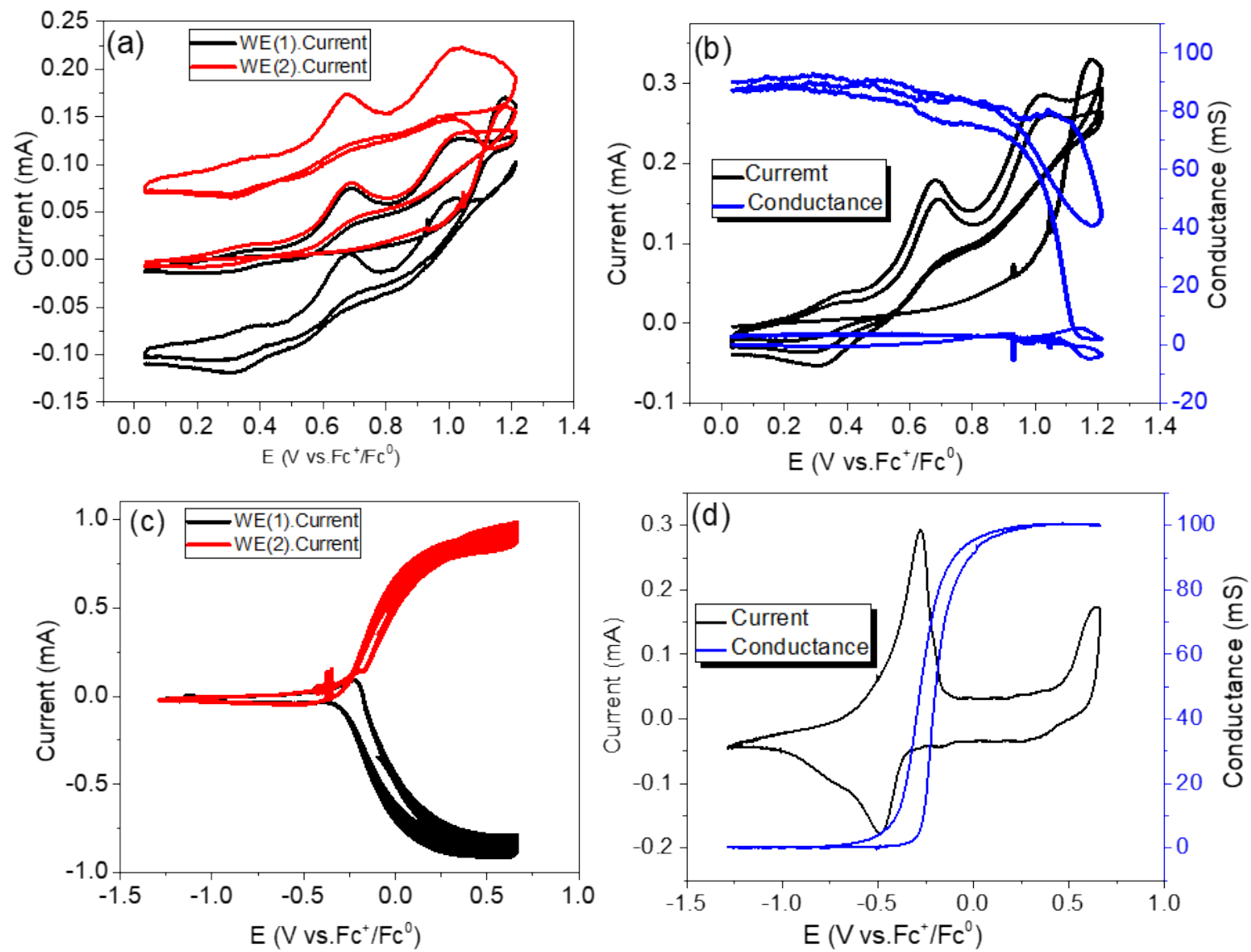

Figure S23. Q-PEDOT (a) Current on the two working electrodes during polymerization on AuIDA in $5 \mathrm{mM}$ monomer $0.1 \mathrm{M} \mathrm{TBAPF} / \mathrm{MeCN}$ solution at $0.05 \mathrm{~V} / \mathrm{s}$ with a potential bias of $1 \mathrm{mV}$. (b) the corresponding $\mathrm{CV}$ and conductance during polymerization. (c) Current on the two working electrodes during characterization on $\mathrm{Au}-\mathrm{IDA}$ in $0.1 \mathrm{M} \mathrm{LiClO} / \mathrm{MeCN}$ solution at $0.05 \mathrm{~V} / \mathrm{s}$ with a potential bias of $10 \mathrm{mV}$. (d) the corresponding $\mathrm{CV}$ and conductance during characterization. 

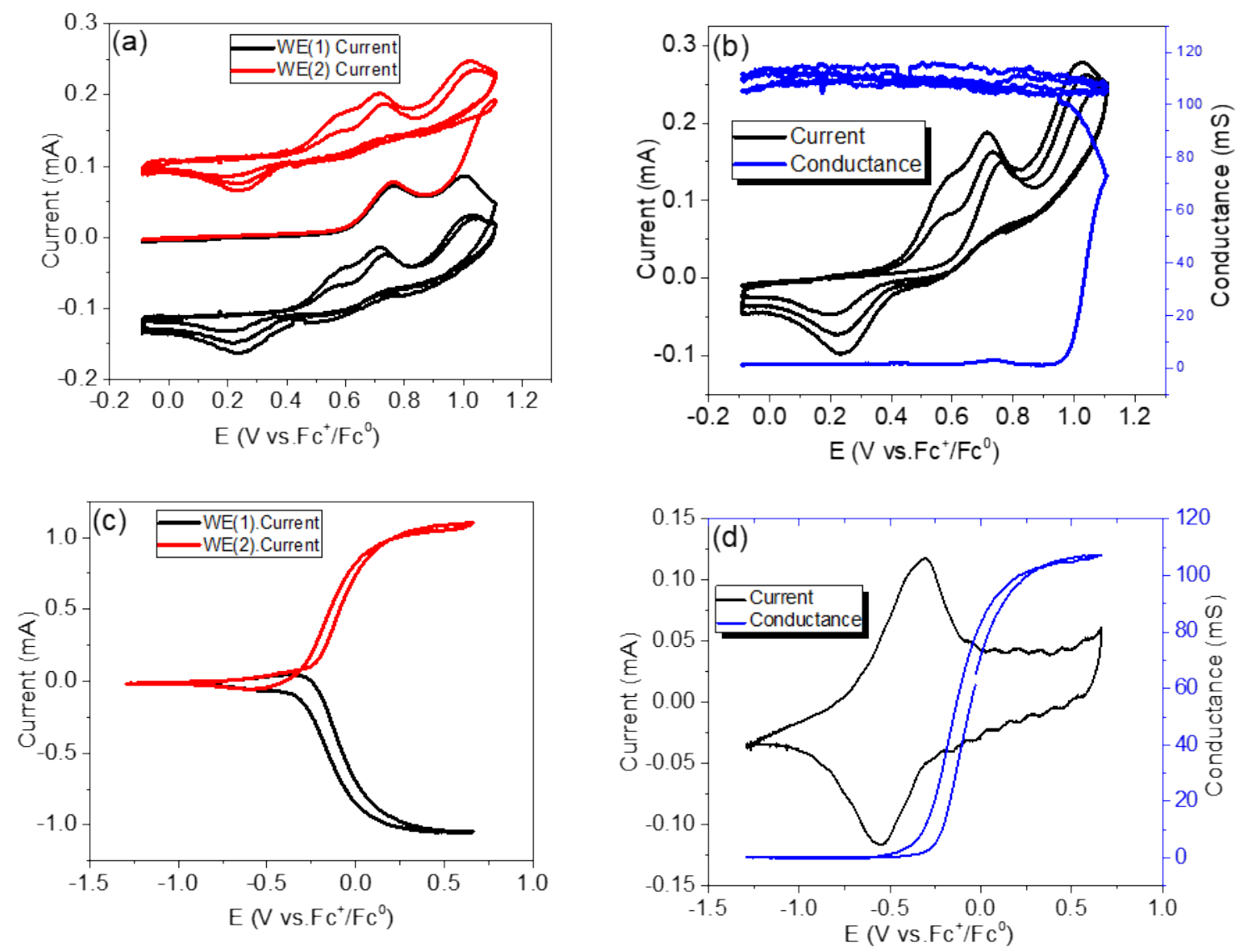

Figure S24. QF-PEDOT (a) Current on the two working electrodes during polymerization on $\mathrm{Au}-\mathrm{IDA}$ in $5 \mathrm{mM}$ monomer $0.1 \mathrm{M} \mathrm{TBAPF} / \mathrm{MeCN}$ solution at $0.05 \mathrm{~V} / \mathrm{s}$ with a potential bias of $1 \mathrm{mV}$. (b) the corresponding $\mathrm{CV}$ and conductance during polymerization. (c) Current on the two working electrodes during characterization on $\mathrm{Au}-\mathrm{IDA}$ in $0.1 \mathrm{M} \mathrm{LiClO} / \mathrm{MeCN}$ solution at $0.05 \mathrm{~V} / \mathrm{s}$ with a potential bias of $10 \mathrm{mV}$. (d) the corresponding $\mathrm{CV}$ and conductance during 
characterization.
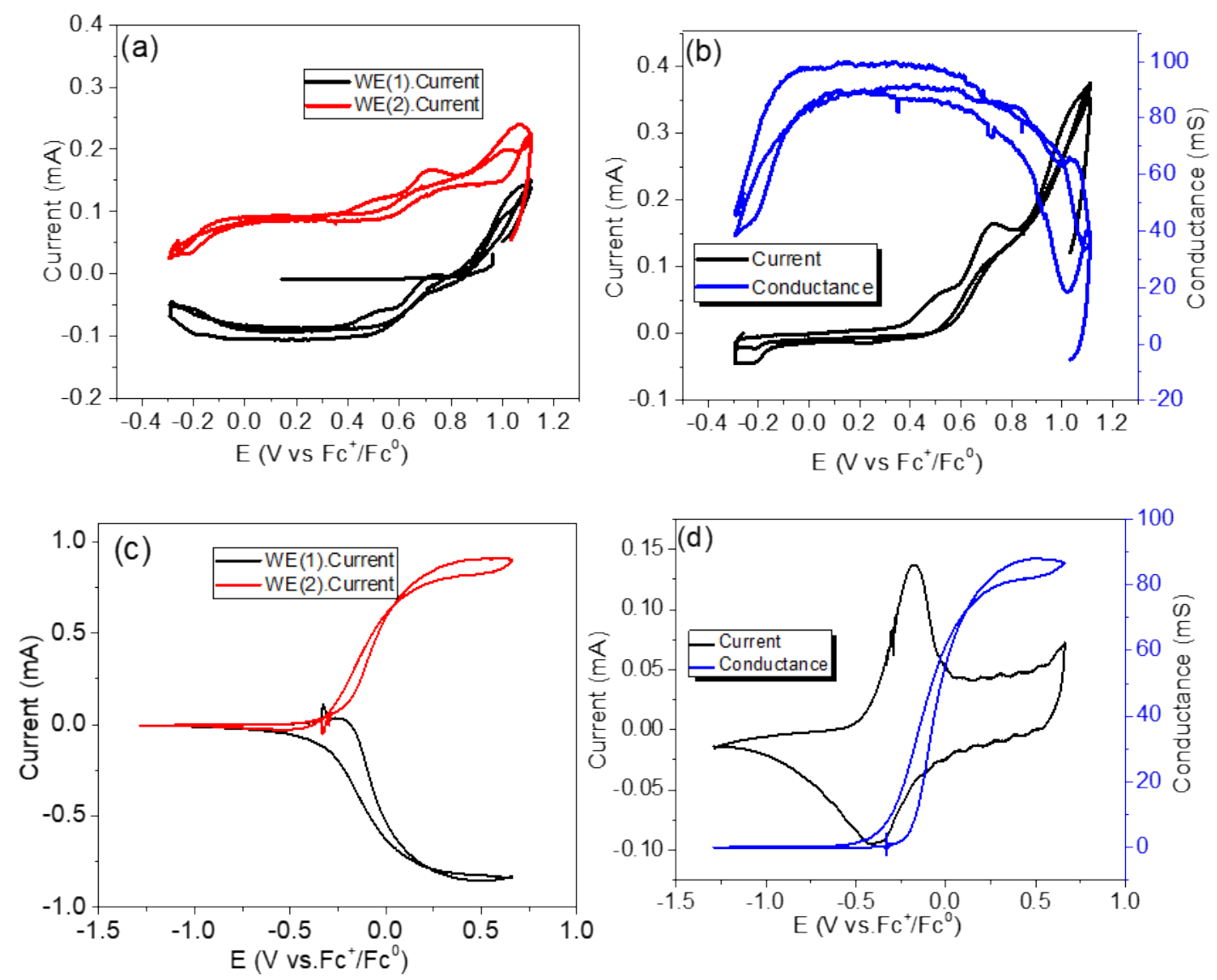

Figure S25. $\mathrm{QF}_{2}-\mathrm{PEDOT}$ (a) Current on the two working electrodes during polymerization on Au-IDA in $5 \mathrm{mM}$ monomer $0.1 \mathrm{M} \mathrm{TBAPF} / \mathrm{MeCN}$ solution at $0.05 \mathrm{~V} / \mathrm{s}$ with a potential bias of $1 \mathrm{mV}$. (b) the corresponding $\mathrm{CV}$ and conductance during polymerization. (c) Current on the two working electrodes during characterization on $\mathrm{Au}-\mathrm{IDA}$ in $0.1 \mathrm{M} \mathrm{LiClO} / \mathrm{MeCN}$ solution at $0.05 \mathrm{~V} / \mathrm{s}$ with a potential bias of $10 \mathrm{mV}$. (d) the corresponding $\mathrm{CV}$ and conductance during characterization. 

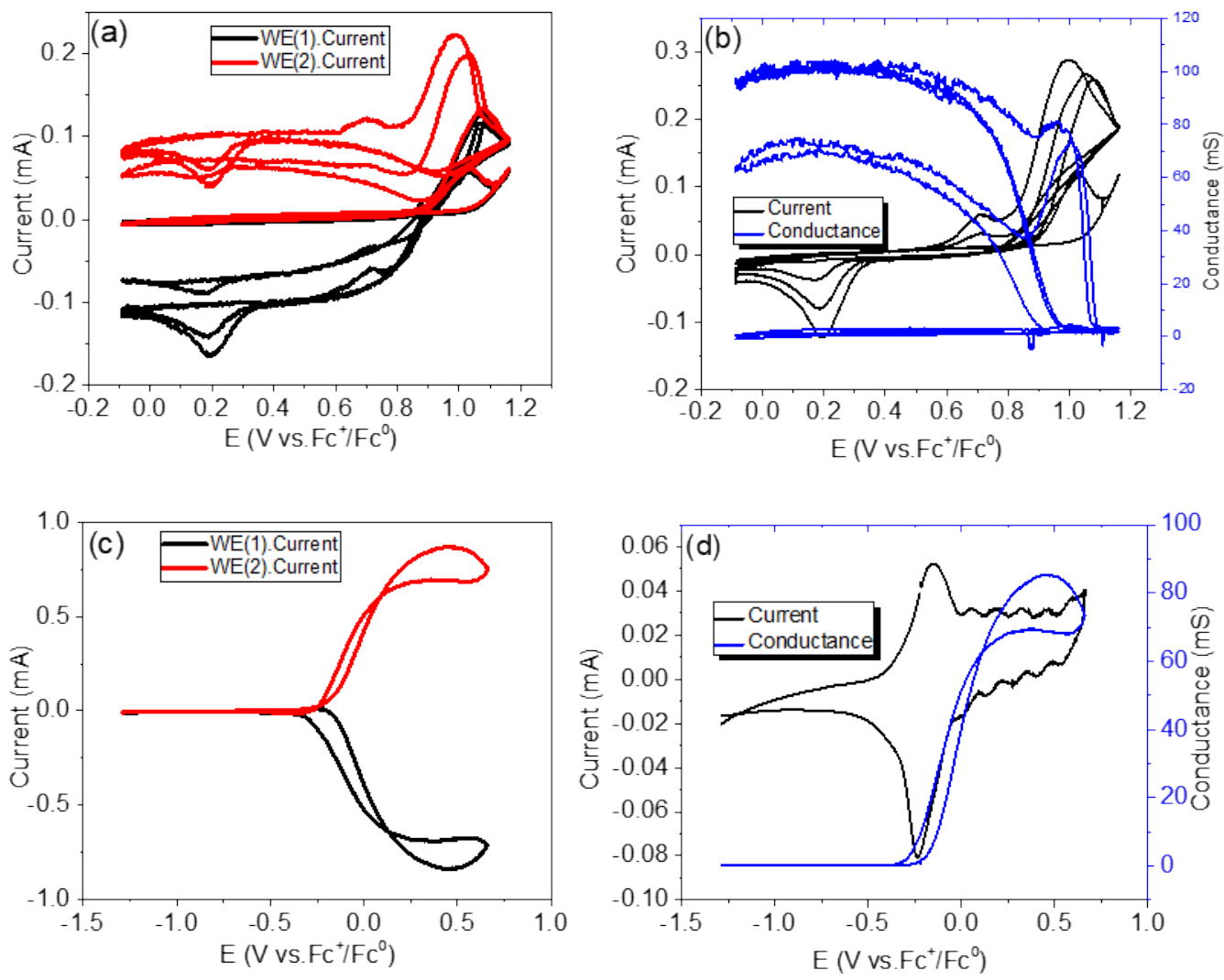

Figure S26. $\mathrm{Q}\left(\mathrm{CF}_{3}\right)_{2}$ - PEDOT (a) Current on the two working electrodes during polymerization on $\mathrm{Au}$-IDA in $5 \mathrm{mM}$ monomer $0.1 \mathrm{M} \mathrm{TBAPF}_{6} / \mathrm{MeCN}$ solution at $0.05 \mathrm{~V} / \mathrm{s}$ with a potential bias of $1 \mathrm{mV}$. (b) the corresponding $\mathrm{CV}$ and conductance during polymerization. (c) Current on the two working electrodes during characterization on $\mathrm{Au}-\mathrm{IDA}$ in $0.1 \mathrm{M} \mathrm{LiClO} / \mathrm{MeCN}$ solution at $0.05 \mathrm{~V} / \mathrm{s}$ with a potential bias of $10 \mathrm{mV}$. (d) the corresponding $\mathrm{CV}$ and conductance during characterization. 
In situ conductance measurements in $0.1 \mathrm{M} \mathrm{TBAClO} / \mathrm{TeCN}_{4}$ for Q-PEDOT, QF-EDOT, $\mathrm{QF}_{2}-\mathrm{EDOT}$ and $\mathrm{Q}\left(\mathrm{CF}_{3}\right)_{2}-\mathrm{EDOT}$
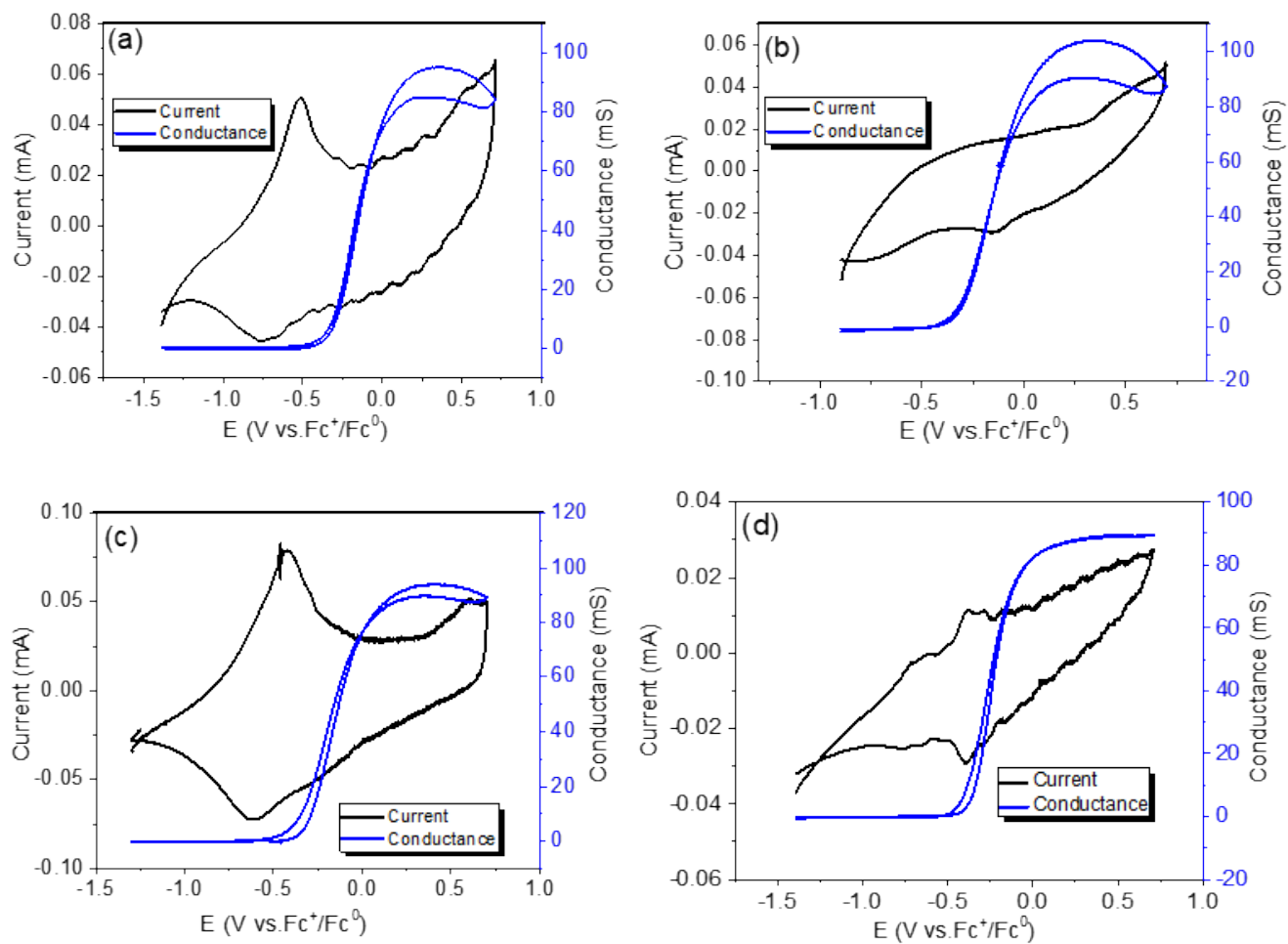

Figure S27. Conductance (blue) and corresponding cyclic voltammetry (black) of (a) Q-PEDOT; (b) QF-PEDOT; (c) $\mathrm{QF}_{2}$-PEDOT; (d) $\mathrm{Q}\left(\mathrm{CF}_{3}\right)_{2}-\mathrm{PEDOT}$ on Au-IDA in $0.1 \mathrm{M} \mathrm{TBAClO} / \mathrm{MeCN}^{-}$ at $0.05 \mathrm{~V} / \mathrm{s}$

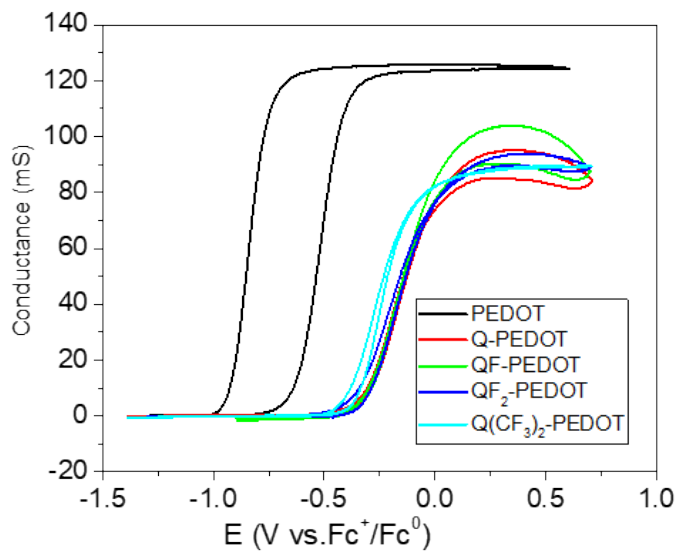

Figure S28. Conductance and corresponding cyclic voltammetry of the four CRPs and PEDOT in on $\mathrm{Au}-\mathrm{IDA} 0.1 \mathrm{M} \mathrm{TBAClO} / \mathrm{MeCN}$ at $0.05 \mathrm{~V} / \mathrm{s}$. 


\section{EQCM for Q-PEDOT, QF-EDOT, $\mathrm{QF}_{2}$-EDOT and $\mathrm{Q}\left(\mathrm{CF}_{3}\right)_{2}$-EDOT}

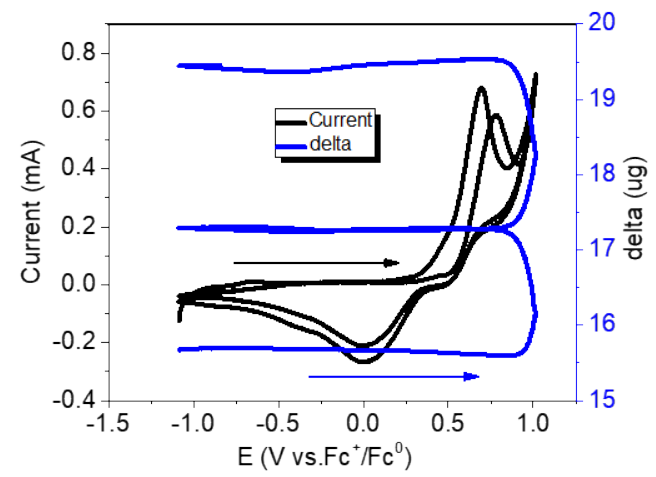

Figure S29. polymerization of Q-PEDOT onto EQCM-Au electrode in $5 \mathrm{mM}$ monomer $0.1 \mathrm{M}$ $\mathrm{TBAPF}_{6} / \mathrm{MeCN}$ electrolyte, scan rate: $0.1 \mathrm{~V} / \mathrm{s}$.
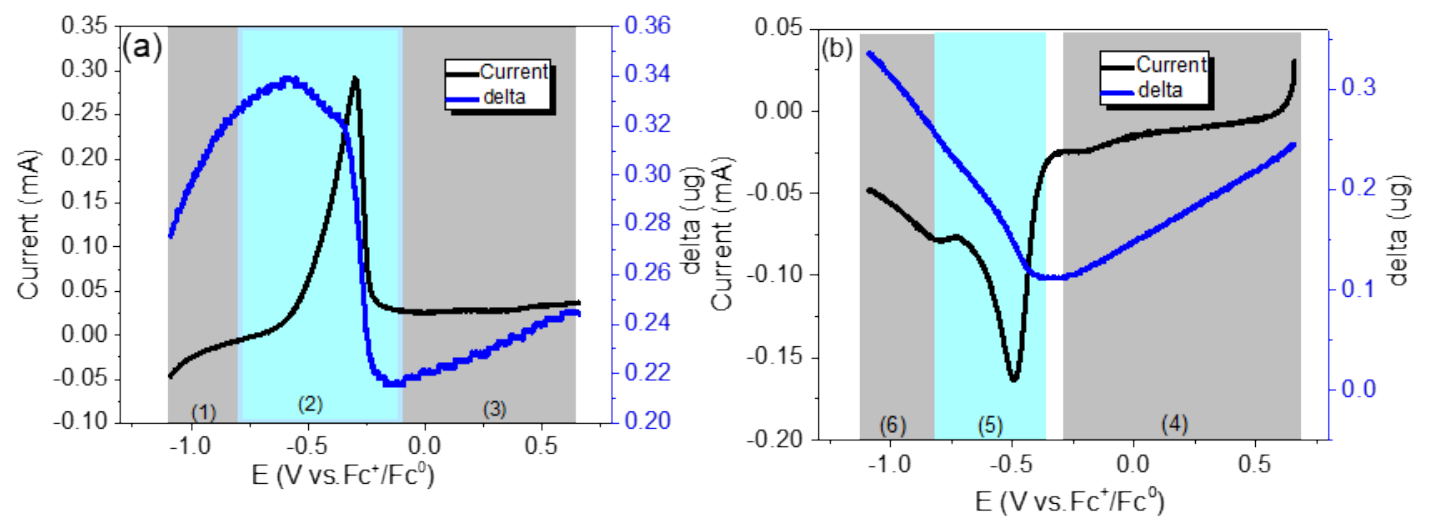

Figure S30. Mass change and recorded current of Q-PEDOT (a) in the oxidative scan, (b) in the reduction scan characterized on $\mathrm{EQCM}(\mathrm{Au})$ in $0.1 \mathrm{M} \mathrm{LiClO}_{4} / \mathrm{MeCN}$ at $0.1 \mathrm{~V} / \mathrm{s}$.

Figure S29 shows the polymerization CV on EQCM-Au and the corresponding mass change. An obvious mass increase was observed above $0.9 \mathrm{~V}$, indicating that polymer builds up at the electrode. Figure S30 (a) shows the mass change of the Q-PEDOT oxidation process. The mass change can be divided into three parts, mass increase in the grey part at the two shoulders is attributed to polymer backbone doping. Mass decrease in the blue part is attributed to quinone oxidation. In region (1), a large mass increase is observed, which is attributed to counter ions $\mathrm{ClO}_{4}^{-}$uptaken to balance the positive charge on the polymer backbone, indicating that the polymer backbone has been doped below $-0.8 \mathrm{~V}$. Mass decrease upon quinone oxidation in the blue region is attributed to $\mathrm{Li}^{+}$repulsion from the $\mathrm{Li}_{2} \mathrm{Q} / \mathrm{LiQ}$ and the $\mathrm{LiQ} / \mathrm{Q}$ redox reactions. Mass change per molar charge of CRPs are summarized in table S2. Mass change per molar 
charge above $0 \mathrm{~V}$ and below $-0.8 \mathrm{~V}$ for all the four polymers is less than $99.5 \mathrm{~g} / \mathrm{mol}\left(\mathrm{M}\left(\mathrm{ClO}_{4}^{-}\right)\right)$, signifying that charge compensation involves both anion uptake and cation expulsion. For QPEDOT, below $-0.8 \mathrm{~V}, 52 \%$ of the positive charge on the polymer chain is compensated by the $\mathrm{ClO}_{4}^{-}$uptake and $48 \%$ is compensated by $\mathrm{Li}^{+}$expulsion. It is noteworthy that mass keeps increasing drastically in the dedoped region (6) and mass change per molar charge in region (6) is similar to that in region (5), indicating that $\mathrm{Li}^{+}$is uptaken and the broad peak is the second reduction of quinone $\mathrm{LiQ} / \mathrm{Li}_{2} \mathrm{Q}$ which extends into the low potential region with a tail in $\mathrm{CV}$
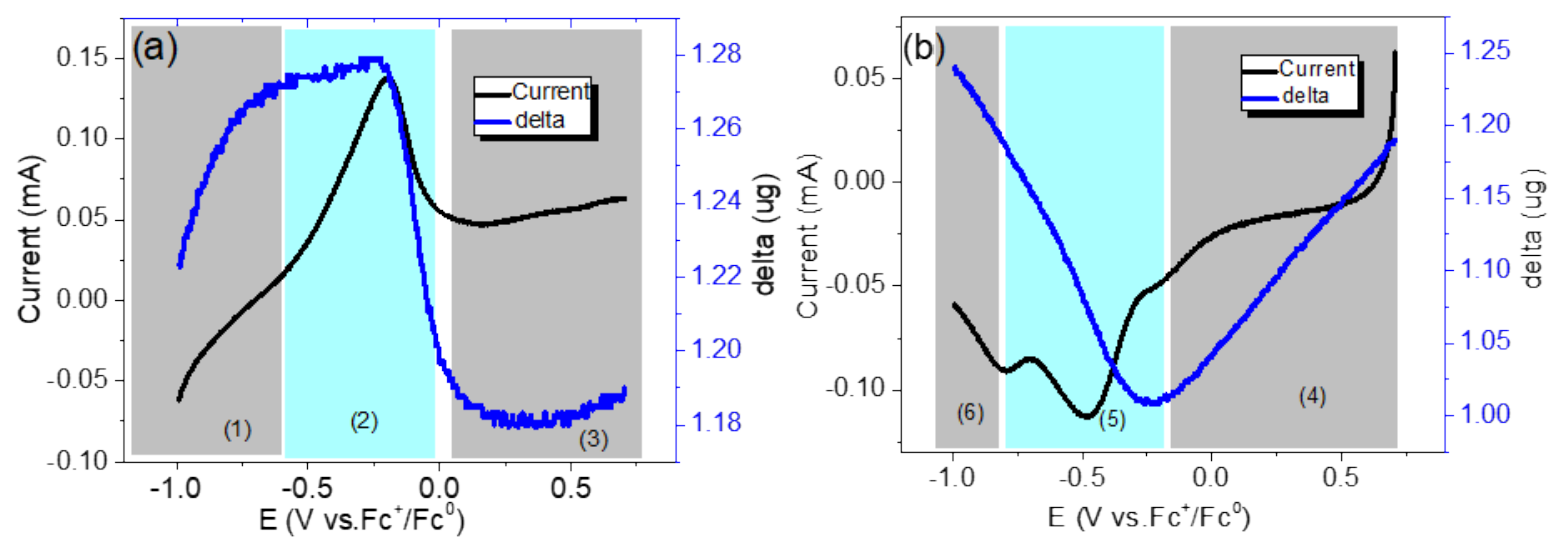

Figure S31. Mass change and recorded current of QF-PEDOT in the (a) oxidation and (b) reduction scans characterized on $\mathrm{EQCM}(\mathrm{Au})$ in $0.1 \mathrm{M} \mathrm{LiClO}_{4} / \mathrm{MeCN}$ at $0.1 \mathrm{~V} / \mathrm{s}$.
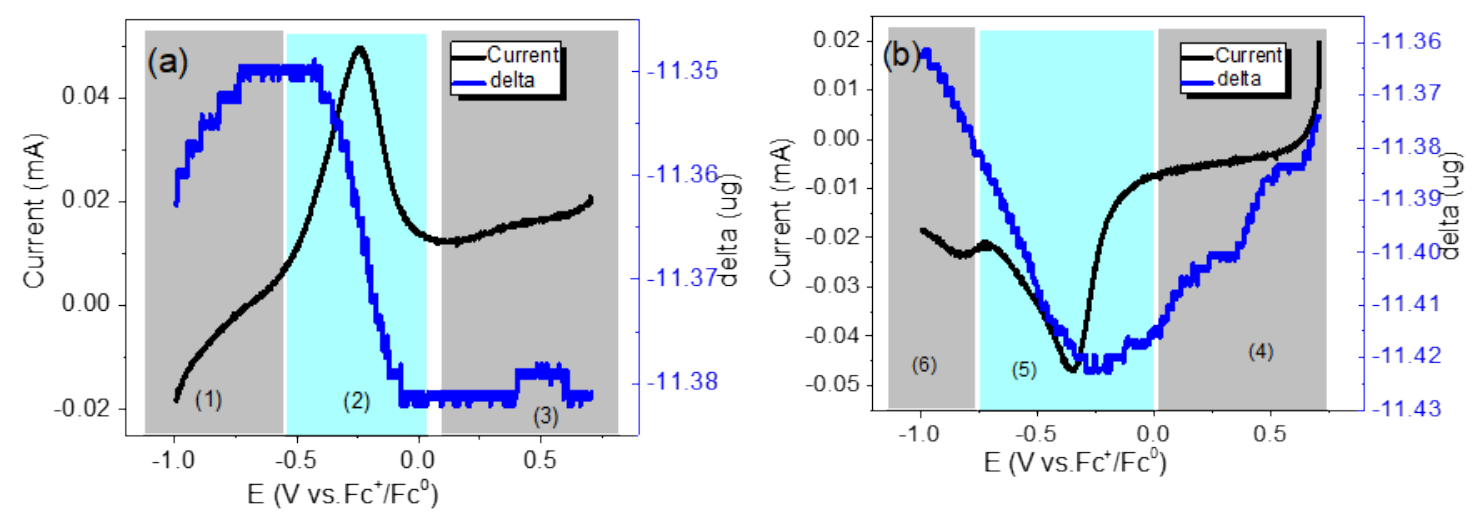

Figure S32. Mass change and recorded current of $\mathrm{QF}_{2}-\mathrm{PEDOT}$ in the (a) oxidation and (b) reduction scans characterized on EQCM $(\mathrm{Au})$ in $0.1 \mathrm{M} \mathrm{LiClO}_{4} / \mathrm{MeCN}$ at $0.1 \mathrm{~V} / \mathrm{s}$ 

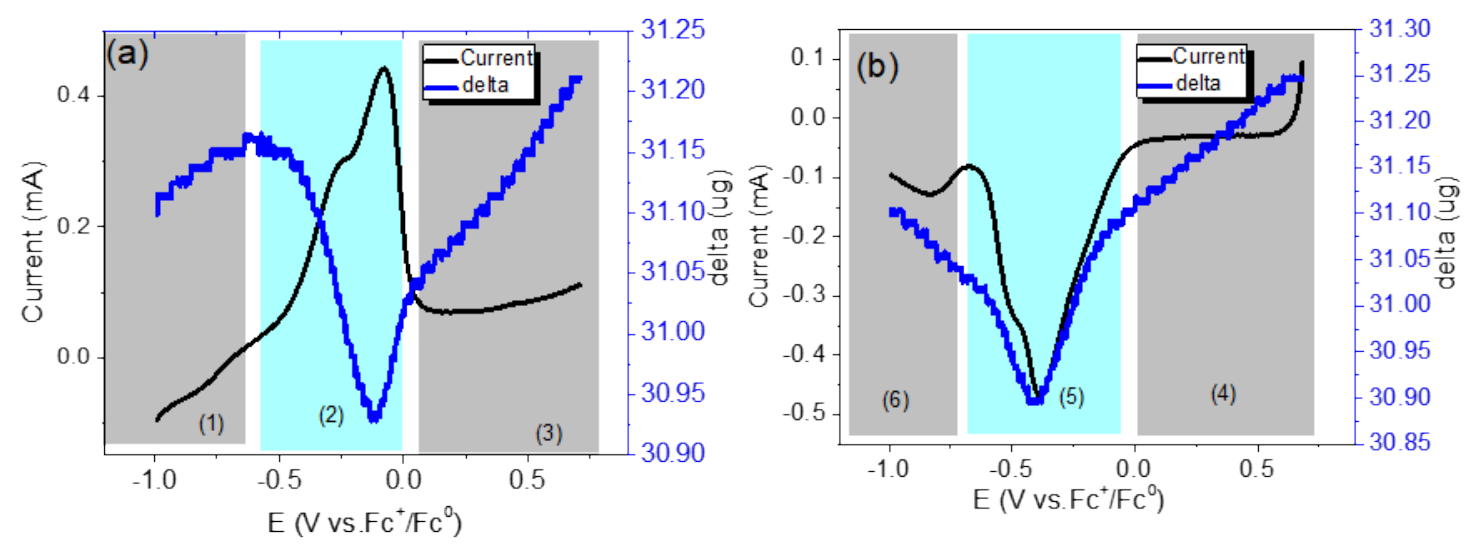

Figure S33. Mass change and recorded current of $\mathrm{Q}\left(\mathrm{CF}_{3}\right)_{2}-\mathrm{PEDOT}$ in the (a) oxidation and (b) reduction scans characterized on $\operatorname{EQCM}(\mathrm{Au})$ in $0.1 \mathrm{M} \mathrm{LiClO}_{4} / \mathrm{MeCN}$ at $0.1 \mathrm{~V} / \mathrm{s}$.

Table S2. Mass change per molar charge of CRPs characterized in $0.1 \mathrm{M} \mathrm{LiClO}_{4} / \mathrm{MeCN}$, (1)-(6) in different potential regions.

\begin{tabular}{|l|l|l|l|l|l|l|}
\hline Slope g/mol & $(1)$ & $(2)$ & $(3)$ & $(4)$ & $(5)$ & $(6)$ \\
\hline Q-PEDOT & 48 & -18 & 5 & -49 & 17 & 29 \\
\hline QF-PEDOT & 30.0 & -10.8 & 1.6 & -48.3 & 17.6 & 17.1 \\
\hline $\mathrm{QF}_{2}$-PEDOT & 26.5 & -20.7 & 0.71 & -42.6 & 5.5 & 19.1 \\
\hline $\mathrm{Q}\left(\mathrm{CF}_{3}\right)_{2}$-PEDOT & 1.23 & -1.36 & 1.45 & -2.5 & 1.04 & 0.94 \\
\hline
\end{tabular}

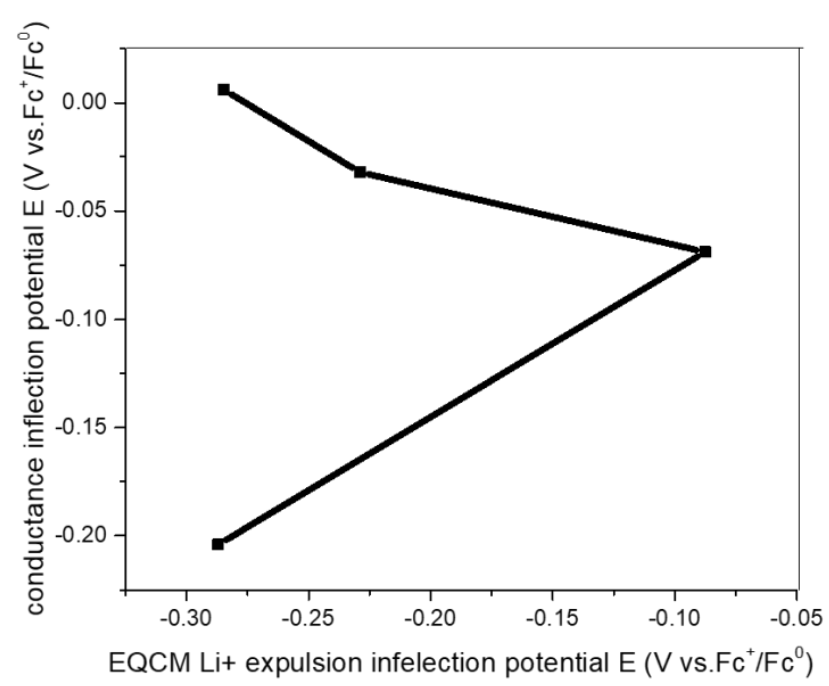

Figure S34. Plot of $\mathrm{Li}_{2} \mathrm{Q}$ oxidation-induced $\mathrm{Li}^{+}$repulsion potential in EQCM and conductance inflection potential. 
In situ spectroelectrochemistry of PEDOT, Q-PEDOT, QF-EDOT, QF ${ }_{2}$-EDOT and $\mathrm{Q}\left(\mathrm{CF}_{3}\right)_{2}$-EDOT
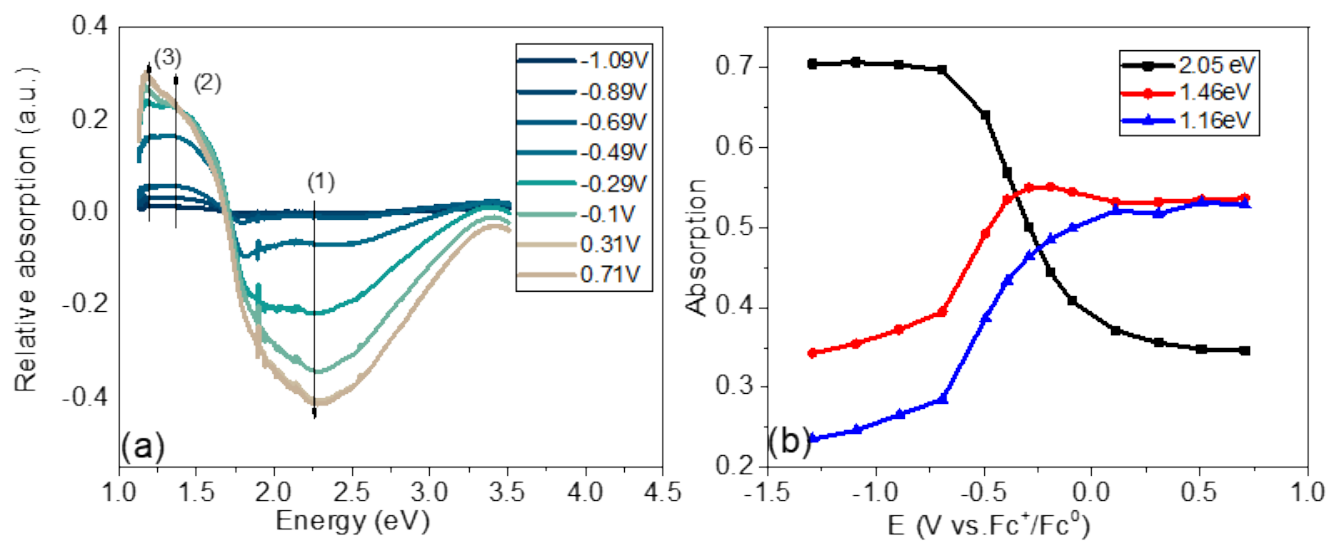

Figure S35. (a) Normalized UV-vis spectroscopy of PEDOT on ITO at different potentials (vs $\left.\mathrm{Fc}^{+} / \mathrm{Fc}^{0}\right)$ in $\left.0.1 \mathrm{M} \mathrm{LiClO}_{4} / \mathrm{MeCN}\right)$. The relative absorbance is a deduction of the absolute absorbance at a given potential and the absorbance at $-1.2 \mathrm{~V}\left(\mathrm{vs} \mathrm{Fc}^{+} / \mathrm{Fc}^{0}\right)$. (b) The absolute absorbance of different transitions in PEDOT.
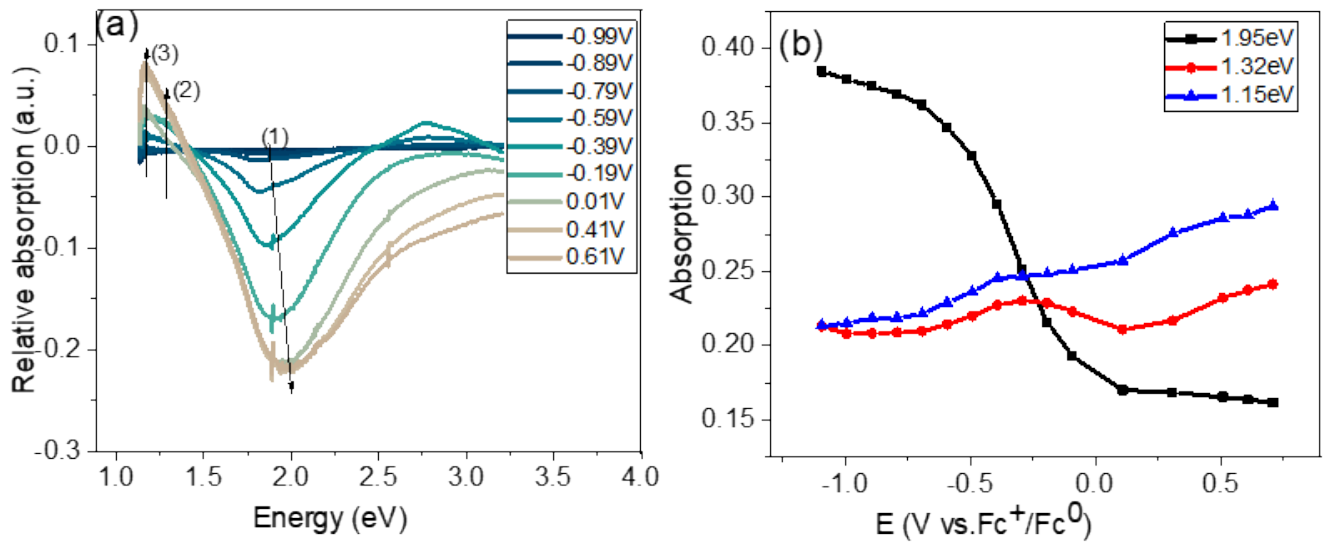

Figure S36. (a) Normalized UV-vis spectroscopy of Q-PEDOT on ITO at different potentials (vs $\left.\mathrm{Fc}^{+} / \mathrm{Fc}^{0}\right)$ in $0.1 \mathrm{M} \mathrm{LiClO} / \mathrm{MeCN}$ ). The relative absorbance is a deduction of the absolute absorbance at a given potential and the absorbance at $-1.2 \mathrm{~V}\left(\mathrm{vs} . \mathrm{Fc}^{+} / \mathrm{Fc}^{0}\right)$. (b) The absolute absorbance of different transitions in Q-PEDOT. 

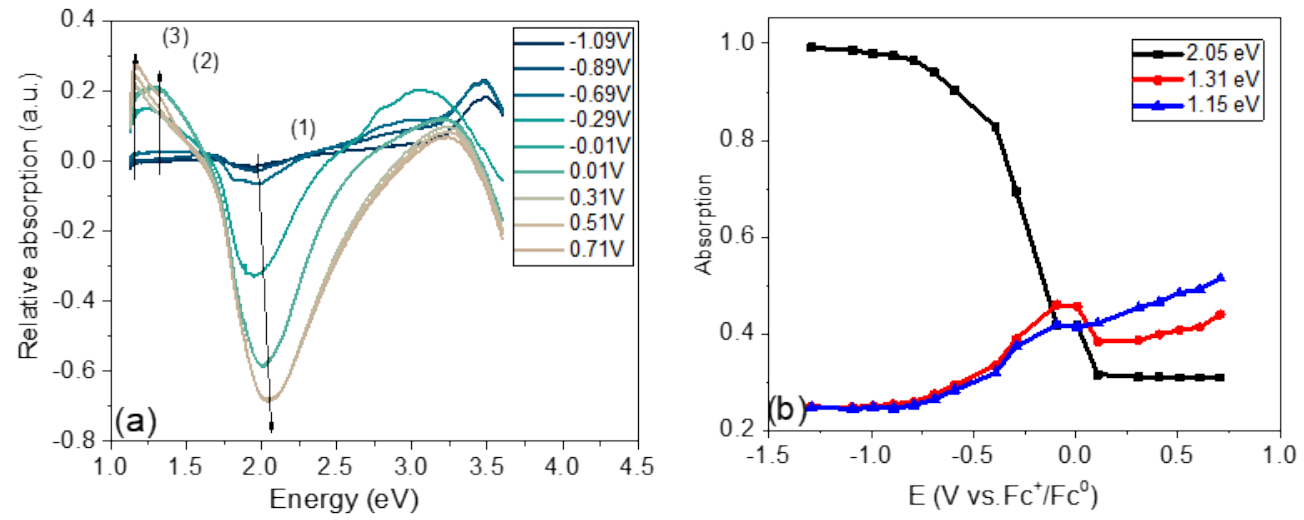

Figure S37. (a) Normalized UV-vis spectroscopy of QF-PEDOT on ITO at different potential $\left(\mathrm{vs} \mathrm{Fc}^{+} / \mathrm{Fc}^{0}\right)$ in $\left.0.1 \mathrm{M} \mathrm{LiClO}_{4} / \mathrm{MeCN}\right)$. The relative absorbance is a deduction of the absolute absorbance at a given potential and the absorbance at $-1.2 \mathrm{~V}\left(\mathrm{vs} \cdot \mathrm{Fc}^{+} / \mathrm{Fc}^{0}\right)$. (b) The absolute absorbance of different transitions in QF-PEDOT.
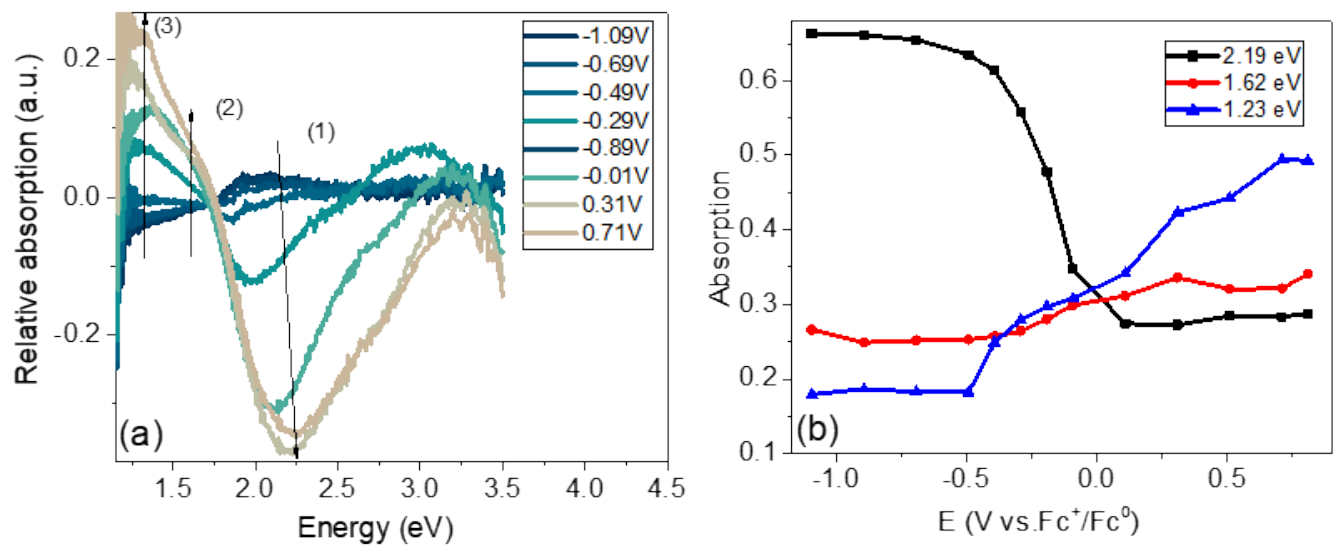

Figure S38. (a) Normalized UV-vis spectroscopy of $\mathrm{QF}_{2}-\mathrm{PEDOT}$ on ITO at different potentials $\left(\mathrm{vs} \mathrm{Fc}^{+} / \mathrm{Fc}^{0}\right)$ in $\left.0.1 \mathrm{M} \mathrm{LiClO}_{4} / \mathrm{MeCN}\right)$. The relative absorbance is a deduction of the absolute absorbance at a given potential and the absorbance at $-1.2 \mathrm{~V}\left(\mathrm{vs} . \mathrm{Fc}^{+} / \mathrm{Fc}^{0}\right)$. (b) The absolute absorbance of different transitions in $\mathrm{QF}_{2}$-PEDOT. 

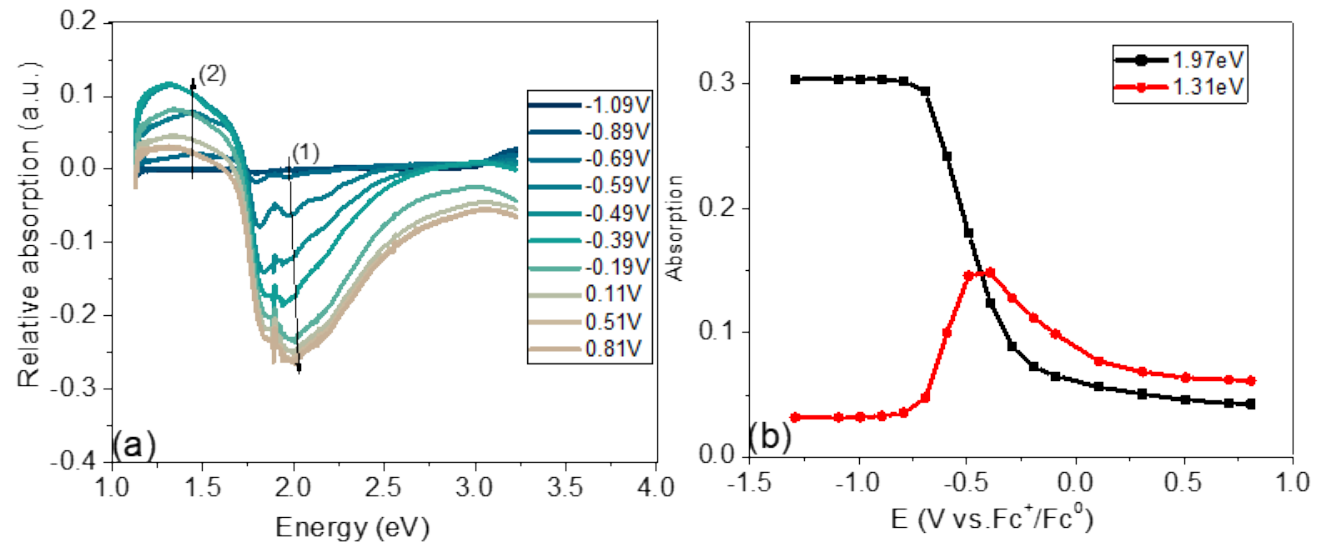

Figure S39. (a) Normalized UV-vis spectroscopy of $\mathrm{Q}\left(\mathrm{CF}_{3}\right)_{2}-\mathrm{PEDOT}$ on ITO at different potential $\left(\mathrm{vs} \mathrm{Fc}^{+} / \mathrm{Fc}^{0}\right)$ in $\left.0.1 \mathrm{M} \mathrm{LiClO}_{4} / \mathrm{MeCN}\right)$. The relative absorbance is a deduction of the absolute absorbance at a given potential and the absorbance at $-1.2 \mathrm{~V}$ ( $\left(\mathrm{vs}^{\mathrm{F}} \mathrm{Fc}^{+} / \mathrm{Fc}^{0}\right.$ ). (b) The absolute absorbance of different transitions in $\mathrm{Q}\left(\mathrm{CF}_{3}\right)_{2}$-PEDOT. 


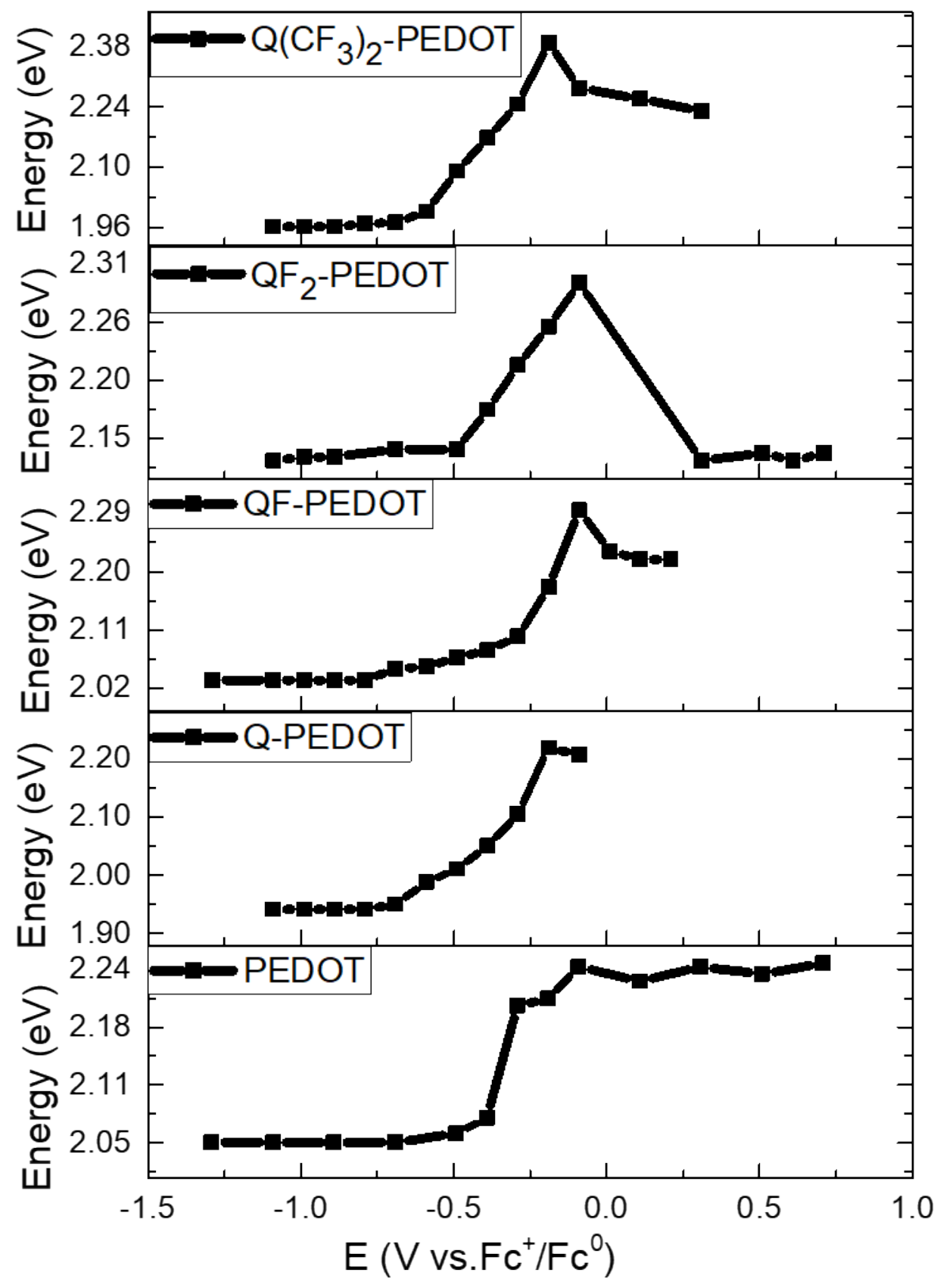

Figure S40. Maximum absorption energy of CB-VB transition in in situ UV-vis measurement at different potential, the data was obtained from figure S33-S35. 


\section{EPR results for Q-PEDOT and $Q\left(\mathrm{CF}_{3}\right)_{2}$-EDOT}

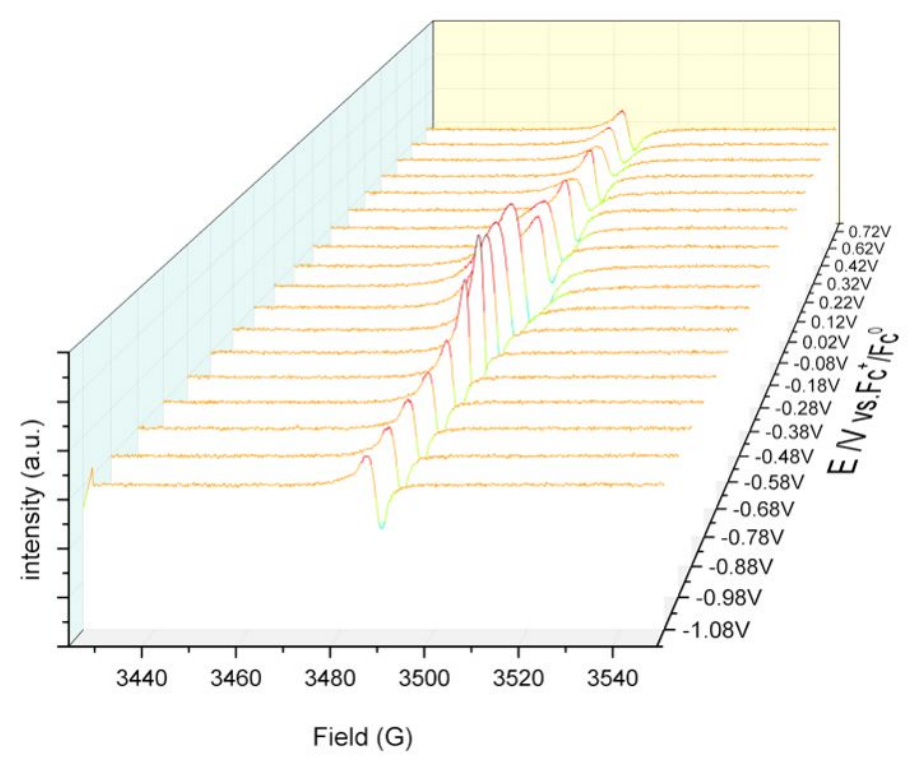

Figure S41. EPR spectra of $\mathrm{Q}\left(\mathrm{CF}_{3}\right)_{2}-\mathrm{PEDOT}$ in $0.1 \mathrm{M} \mathrm{LiClO} / \mathrm{MeCN}_{4}$ on Pt wire at different potential. EPR conditions: microwave frequency $9.77 \mathrm{GHz}$, microwave power $5 \mathrm{~mW}$, modulation amplitude $2 \mathrm{G}$, room temperature.

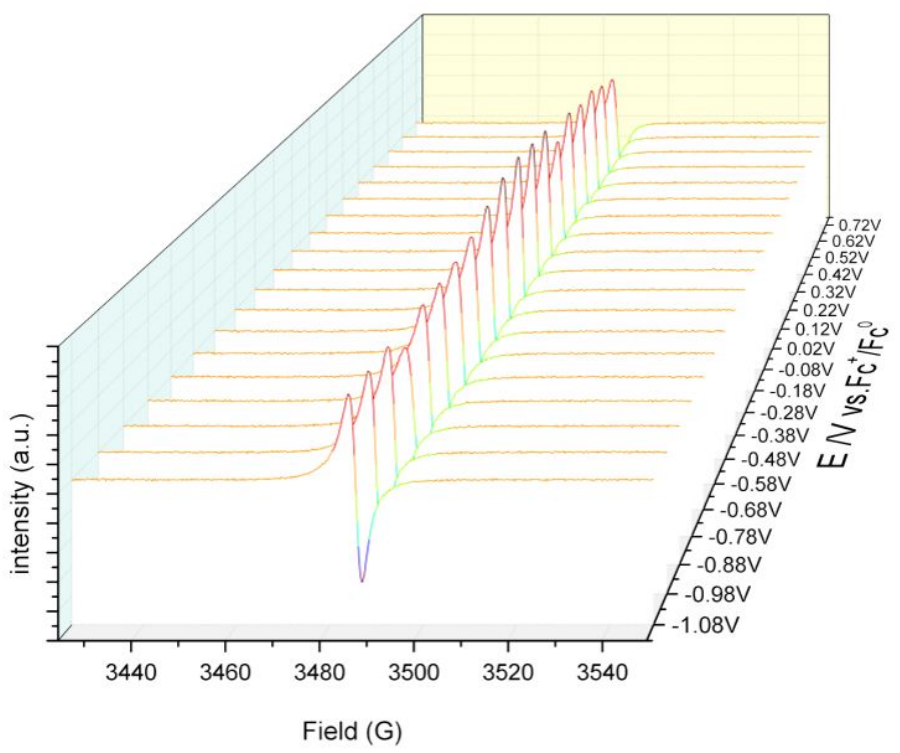

Figure S42. EPR spectra of Q-PEDOT in $0.1 \mathrm{M} \mathrm{LiClO}_{4} / \mathrm{MeCN}$ on Pt wire at different potential. EPR conditions as in Fig. S38. 

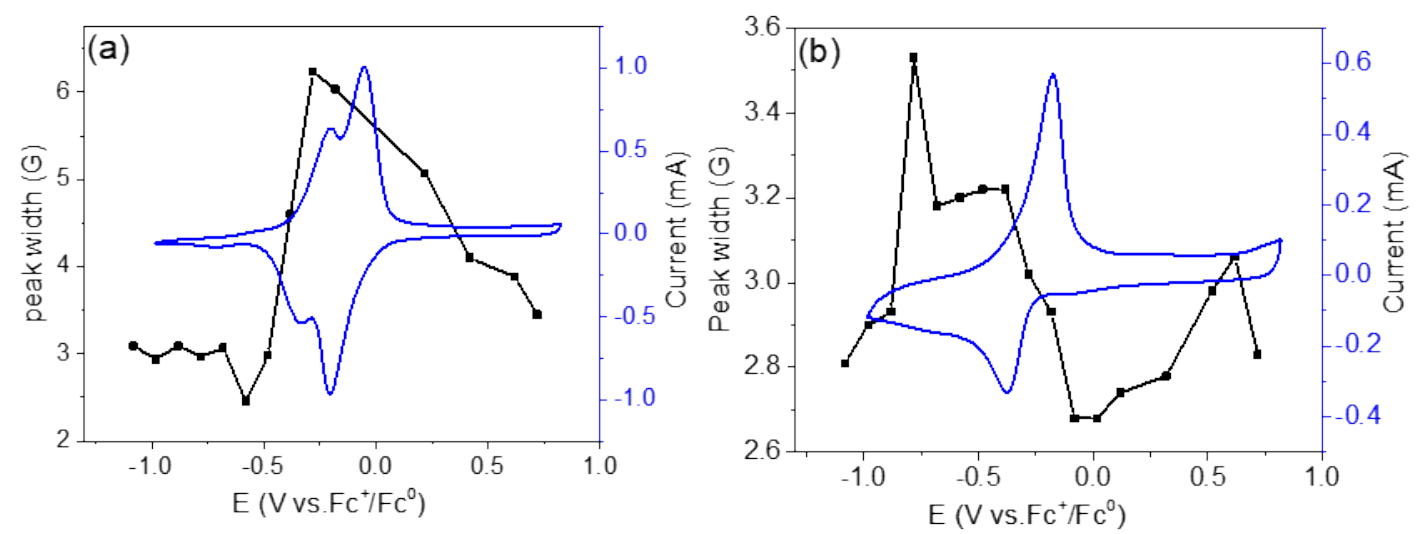

Figure S43. Peak width from EPR measurement on Pt wire in $0.1 \mathrm{M} \mathrm{LiClO}_{4} / \mathrm{MeCN}$ at different potentials of (a) Q $\left(\mathrm{CF}_{3}\right)_{2}$-PEDOT and (b) Q-PEDOT. Blue lines shows the $\mathrm{CV}$ response of the corresponding electrodes measured prior to the EPR experiment in a beaker cell in $0.1 \mathrm{M}$ $\mathrm{LiClO}_{4} / \mathrm{MeCN}$ at $0.1 \mathrm{~V} / \mathrm{s}$

SEM image of $\mathrm{Q}\left(\mathrm{CF}_{3}\right)_{2}$-PEDOT.

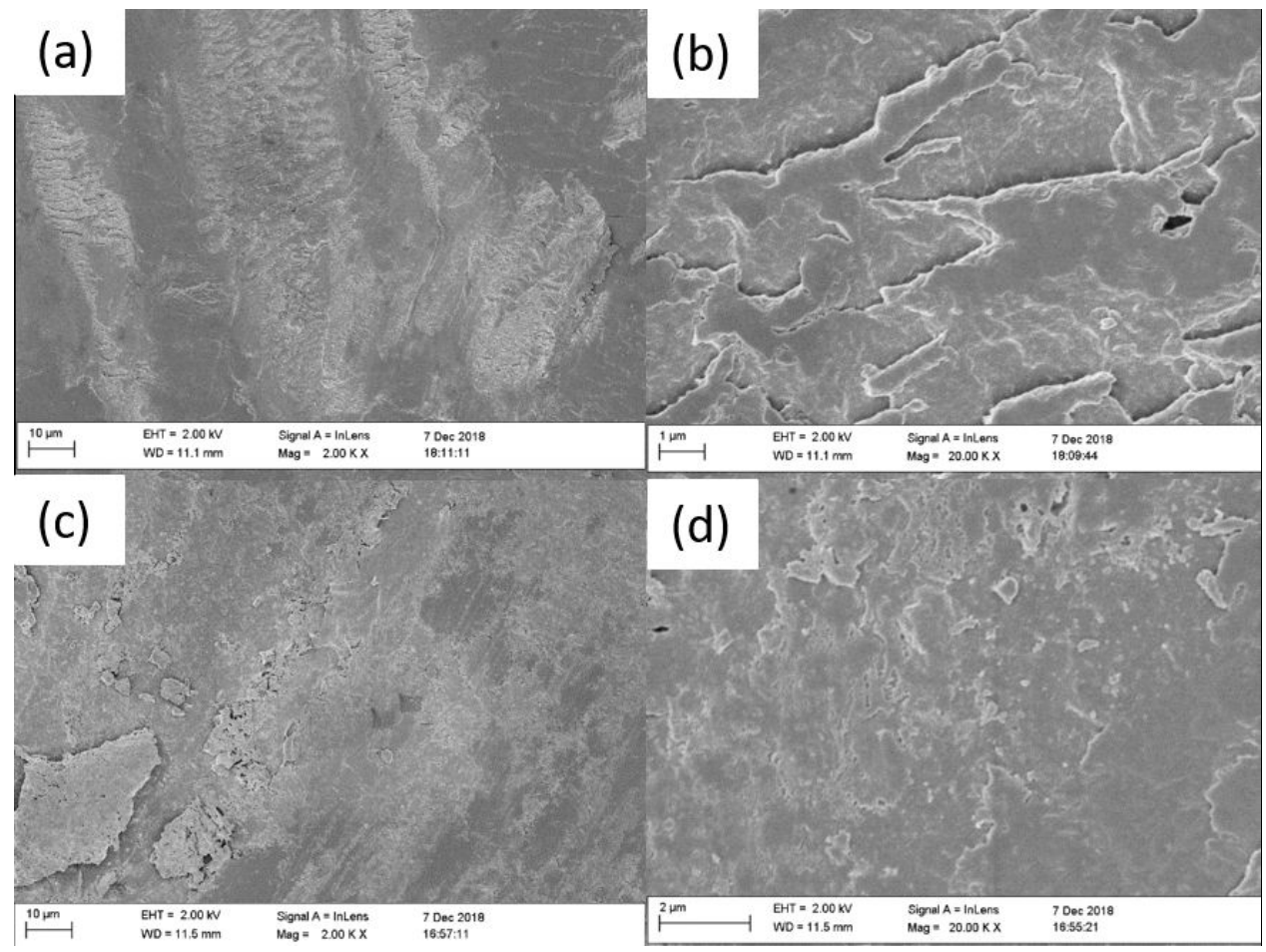

Figure S44. Scanning electron spectroscopy images of $(\mathrm{a}, \mathrm{b})$ pristine and $(\mathrm{c}, \mathrm{d})$ cycled $\mathrm{Q}\left(\mathrm{CF}_{3}\right)_{2}$ PEDOT. 


\section{Reference}

(1) Sterby, M.; Emanuelsson, R.; Huang, X.; Gogoll, A.; Strømme, M.; Sjödin, M.

Characterization of PEDOT-Quinone Conducting Redox Polymers for Water Based Secondary Batteries. Electrochimica Acta 2017, 235, 356-364.

(2) Huang, X.; Yang, L.; Emanuelsson, R.; Bergquist, J.; Strømme, M.; Sjödin, M.; Gogoll, A. A Versatile Route to Polythiophenes with Functional Pendant Groups Using Alkyne Chemistry. Beilstein J. Org. Chem. 2016, 7, 2682-2688

(3) Hünig, S.; Bau, R.; Kemmer, M.; Meixner, H.; Metzenthin, T.; Peters, K.; Sinzger, K.; Gulbis, J. 2,5-Disubstituted N,NJ-Dicyanoquinone Diimines (DCNQIs)-Syntheses, and Redox Properties. Eur. J. Org. Chem. 1998, 14, 335-348

(4) Matsubara, H.; Maegawa, T.; Kita, Y.; Yokoji, T.; Nomoto, A. Synthesis and Properties of Fluorous Benzoquinones and Their Application in Deprotection of Silyl Ethers. Org. Biomol. Chem. 2014, 12 (29), 5442-5447.

(5) Kim, Y.; Swager, T. M. Ultra-Photostable n-Type PPVs. Chemical Communications. 2005, 3, 372-374.

(6) Duan, J.; Zhang, L. H.; Dolbier, Jr., W. R. A Convenient New Method for the Bromination of Deactivated Aromatic Compounds. Synlett 1999, 1999 (8), 1245-1246.

(7) Magano, J.; Chen, M. H.; Clark, J. D.; Nussbaumer, T. 2-(Diethylamino)Ethanethiol, a New Reagent for the Odorless Deprotection of Aromatic Methyl Ethers. The Journal of Organic Chemistry 2006, 71 (18), 7103-7105.

(8) Miller, J. A.; Coleman, M. C.; Matthews, R. S. Synthesis of 2,6Bis(Trifluoromethyl)Phenol and Its Elaboration into Metabolism-Resistant Analogs of Tebufelone. The Journal of Organic Chemistry 1993, 58 (9), 2637-2639.

(9) Karlsson, C.; Huang, H.; Strømme, M.; Gogoll, A.; Sjödin, M. Ion- and Electron Transport in Pyrrole/Quinone Conducting Redox Polymers Investigated by In Situ Conductivity Methods. Electrochimica Acta 2015, 179, 336-342.

(10) Buttry, D. A.; Ward, M. D. Measurement of Interfacial Processes at Electrode Surfaces with the Electrochemical Quartz Crystal Microbalance. Chemical Reviews 1992, 92 (6), 1355-1379. 